\title{
Forecasting of emerging therapeutic monoclonal antibodies patents based on a decision model
}

\author{
Cristiano Gonçalves Pereira ${ }^{1}$, Joao Ricardo Lavoie ${ }^{2}$, Edwin Garces ${ }^{2}$, Fernanda Basso ${ }^{1}$, Marina \\ Dabić $^{3}$, Geciane Silveira Porto ${ }^{1}$, Tugrul Daim ${ }^{2 *}$
}

1. School of Economics Business Administration and Accounting at Ribeirão Preto, University of Sao Paulo, Ribeirao Preto - SP, Brazil.

2. Engineering and Technology Management Department, Portland State University, Portland - OR, United States

3. Faculty of Economics and Business University of Zagreb, Croatia \& Management Department, Nottingham Trent University, the United Kingdom

\begin{abstract}
Therapeutic monoclonal antibodies (mAbs) market is strongly contributing to the rising growth of the biotechnology industry. Despite the increasing number of inventions over time, a few therapeutic mAbs are currently marketed. This paper focuses on developing an emerging score to select/rank promising therapeutic mAbs patents, based on a hierarchical decision model using expert's opinion. Six attributes related to each factor concerning patent status, patent owner's profile and mAbs medical relevance were analyzed. The desirability levels of each attribute were also assessed. Our data shows the medical relevance factor as the most important, contributing 50\% of the emerging score. Among the attributes, the most important under patent status was proper geographic coverage and wider patent scope; for organization's profile was the preexistence of approved drugs; and for medical relevance, the clinical phase performance. A group of 1053 patents related to therapeutic mAb were scored, and the most promising were concerning combination therapy using immune checkpoint inhibitors. The study has managerial implications related to patent portfolio management and patent valuation, and provides instructions to rank mAbs patents according to the emerging score defined by attribute's importance in order to improve the identification of future innovations pathways.
\end{abstract}

KEYWORDS: Technology Forecasting; Decision-Making Models; Patent Assessment; Biotechnology; Monoclonal Antibodies

\section{INTRODUCTION}

The biotechnology industry is technology emergence sector which facing a remarkable growth recently. The worldwide market was estimated at USD 369.62 billion in 2016 and is projected to reach $\$ 727.1$ billion by 2025 (Grand View Research, 2017). It is remarkably transforming the United States (US) economy, the country with the largest biotech sector. The 
contribution of the industry to the US economy was estimated to represent more than $2 \%$ of the gross domestic product (GDP) and, from 2007 to 2012, the biotech aggregates revenue have grown more than $10 \%$ on annual average rate, much faster than the US general economy (Carlson, 2016). The progress of the industry is mainly motivated by factors such as massive $R \& D$ investments, intense use of intellectual property rights and also the establishment of partnership and strategic alliances (Evens and Kaitin, 2014). High investments in such factors contribute directly to an increased number of biopharmaceuticals in clinical development. There was a rise of $245 \%$ on the number of drug candidates from 2001 to 2012 (PhRMA, 2013). The biggest was seen by the monoclonal antibody (mAb) class which rose $351 \%$ over the 11 years of analysis, starting from 338 molecules under development to 901 in 2012. Monoclonal antibodies are not only the highest biopharmaceuticals class in development, they are also the most approved in the US and Europe (Walsh, 2014). Nevertheless, behind the regulatory steps, resides the strength of intellectual property rights. The commercialization process evaluates a patent value. Gans, and Stern, (2003.p. 348) pointed out that commercialization strategy environment embraces its own vulnerabilities and possible opportunities. Technological spillover enables rivals to follow up original endeavors, and even took advantage of quickly catch up or "invent around" already claimed the original of invention (Chadha \& Oriani, 2010; Liu et al., 2018). Although, real view of the possibility of a patent being affected in litigation prevails unclear without fully examining managerial awareness, which is directed and classified heterogeneously within a company. Ardito et al., 2015 investigated how the costs and benefits of a comprehensive search in green energy general purpose technologies progress depends on structure within two teams, size dimension and geographic distribution across countries. Eusebi and Silberglitt $(2014$, p. 1) defined a possible value metric for technology transfer staff with the emergence s-curve, by classifying patents in positions of their distance from the year of appearance whether they are "leading" or "following" the profitmaking attentiveness in the field and features of patent networks. Due technological uncertainty companies are searching the best model to acquire the relevance and consequence from patent status and in this case the medical significance of the mAbs patent.

The patent universe, especially for mAbs, is extremely vast and diverse which, consequently, result in a discrepancy between the number of drugs that actually reach clinical development and the patented discoveries. Considering the high cost and risk of failure during the clinical development (Morgan et al., 2011), companies need to manage their intellectual property to assess technology value and set strategies to invest on emerging technologies. In 
this regard, decision-making is a fundamental process for drug development companies to select the best alternatives for investment (Jekunen, 2014). Since patents guarantee the exclusivity on the commercial exploration of their technologies, forecasting the most promising mAbs therapies based on their many intrinsic criteria seems a consistent strategy for a biotech company to identify emerging technologies.

Although the subject is relevant, there are few studies that show the association of multicriteria decision-making methods aiming to rank/score technologies on patent-level in biotechnology. And the availability of studies is even more limited when the approach is used to assess the technology potential on a large pool of alternatives of a specific sector such as therapeutic mAbs. The present study comes to add to the current literature by presenting the novelty of associating a hierarchical decision model (HDM) and patent analysis, in order to predict the technology emergence according to an emerging score (ES). Indicators for technology emergence can contribute to R\&D policy and portfolio management, as well as analysis of technology opportunities to indicate priorities and manage innovation (Porter and Detampel, 1995). In the context of this research, the technology emergence that we aim to identify concerns the prediction of new molecules of monoclonal antibodies for therapeutic use, taking into account the quality of the intellectual property involved in the technology, the company's strength to drive any therapy to the late-stage of clinical phase, and the intrinsic molecular and functional characteristics of the mAbs.

In face of that, our research aimed to develop an ES for therapeutic mAbs based on HDM. The score was calculated after expert's quantitation of several factors and its attributes that influence the success of the therapeutic mAbs, and it was used to further assess, rank, and predict promising patents. Firstly, we have identified and described the factors and its related attributes that influence the mAbs success based on literature and expert's opinion. Factors were relative to the attributes of the patent, the company which holds the technology, and clinical relevance of a mAbs. Secondly, their relative importance was quantified based on expert's pair-wise comparison. Finally, we ended up with a list of the overall significance of factors and attributes for a certain patent to be considered emerging. In this case, the alternatives were patents related to therapeutic mAbs, which were scored and ranked to forecast emerging mAbs. The following section brings a literature review discussing and connecting the main topics of our research with the present literature, including also a brief patent landscape of the sector as described by Pereira and Porto (2018). A detailed research framework follows, describing the steps for building, validation, quantification, and application of the model. Next is a section with the results, stating the attribute's relative 
importance, their least and most desirable levels, and the patent scoring highlighting the top 10 most promising technologies according to the model. Finally, we discuss the results pointing its implications, limitations, and scope of applications.

\section{BACKGROUND}

\subsection{Biotechnology industry and the therapeutic monoclonal antibody market}

The biotechnology is one of the fast-growing industries in the world. The growth of the sector is mainly driven by their applications in healthcare, which differs from the traditional pharmaceuticals by the nature of their drugs. While biotechnology companies develop their drugs on a biological basis using living organisms, the pharmaceutical uses traditional chemical-base drugs. Although biotechnology has a wider scope of its applications and higher operating cost (Edelman, 2004), both sectors intersect and complement each other (Rader, 2008).

The major product categories are biopharmaceuticals, which include large-molecule proteins; peptides; monoclonal antibodies; cell, tissue, and genetic therapies; and many others. Most profits from biopharmaceuticals comes from monoclonal antibodies (mAb), which sales in 2016 represented $66 \%$ of the total market (excluding vaccines) - a total of 106.9 billion dollars (La Merie Publishing, 2017). Five of the top 10 drugs sold in 2016 were mAbs (Kennedy et al., 2017).

Monoclonal antibodies are produced by a single clone of lymphocyte B and are designed to target a particular antigen. Therapeutically, mAbs were introduced in the 90's and are currently being used in therapies for cancer, inflammatory, cardiovascular and infectious diseases, organ transplantations, and many other applications. The growth of therapeutic mAbs market was significantly leveraged by the improvement of our understanding of the diseases molecular basis lead by the next-generation sequencing (Cheung et al., 2012; Reddy et al., 2010) associated with techniques such as phage display (Li and Caberoy, 2010; Saggy et al., 2012).

A patent scenario for the therapeutic mAb confirms the growth of the sector. Considering a patent search using the priority year consisting from 1998 to 2017 and the IPC class and subclasses of A61K 39/395 (Medicinal preparations containing antibodies), we found 75,796 patent families, with more than 5,000 inventions/year since 2004 (Fig. 1A). On the other hand, this large number of new inventions is inconsistent with the number of monoclonal antibodies in development. There are only 3,889 new drugs under development or 
already registered or launched, and $70 \%$ of them are in the biological testing phase, the early stage of development (Fig.1 B). Nevertheless, the therapeutic class is facing the fastest approval rate in history, with the record of 10 approvals in 2017, totaling 76 mAbs approved either in US or EU (European Union) at the end of 2017 (The Antibody Society, 2017). And the quantity is about to rise because, at the same period, 9 therapeutics antibodies were undergoing regulatory review, 26 investigational are undergoing evaluation in late-stage clinical studies of non-cancer indications and more 28 for treatment of patients with cancer (Kaplon and Reichert, 2018).
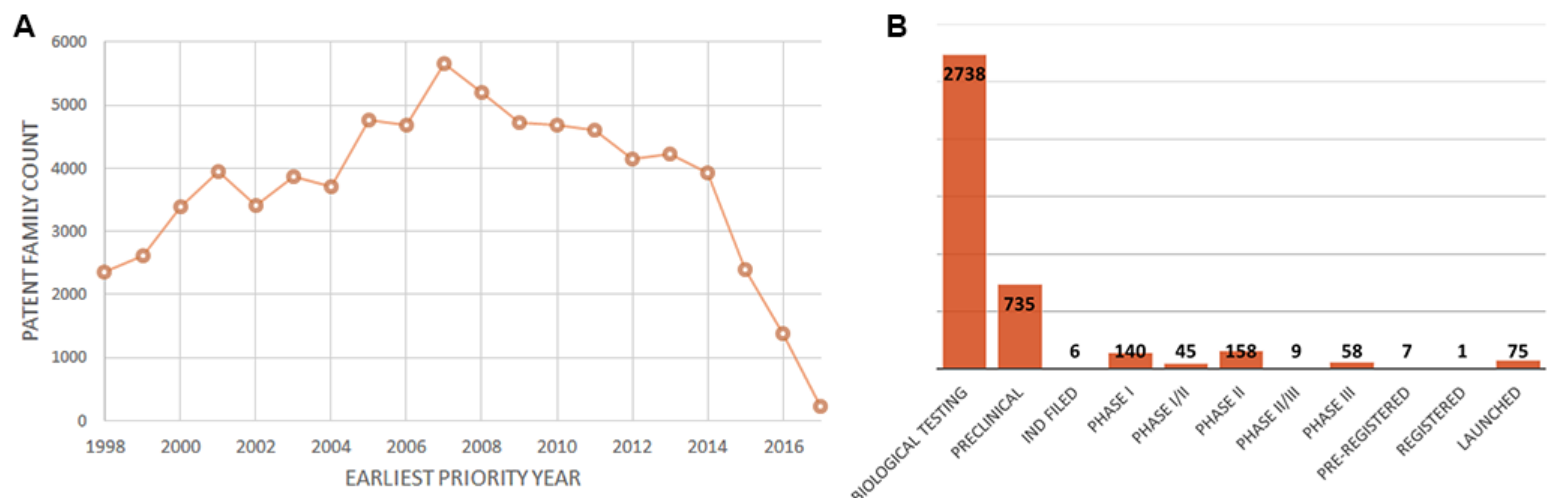

Figure 1: A) Evolution of therapeutic mAbs patent families according to earliest priority year of application (data retrieved from Derwent Innovation). B) Number of therapeutic mAbs under active development including those registered or launched (data retrieved from Clarivate Integrity)

The US contribution to the drug discovery process related to therapeutic mAbs is very expressive. Most of the inventions from 1998 to 2017 comes from the US (56.5\%), far ahead from the subsequent countries, which are Japan (14,28\%) and European applications $(7,96 \%)$ (Fig. 2A). Within the pool of technologies, the Roche group is the main player with 7,5\% of the total, led by Hoffman La Roche and Genentech (an American biotech company acquired by Roche). From the top 20 assignees, 14 are US companies or American units (Fig. 2B). Despite the recent advances on the identification of new targets, the steps from the discovery and development to the commercial production of a new therapeutic mAbs are lengthy and costly (average of 1 billion from preclinical through to market approval), besides being scientifically and technically complex (Elgundi et al., 2017). Even so, it's very worthful for a biotech company to invest this therapeutic mAbs, as they are the major class of biopharmaceutical products worldwide and often the first product candidates advancing to clinical trials (Ecker et al., 2015). 
A

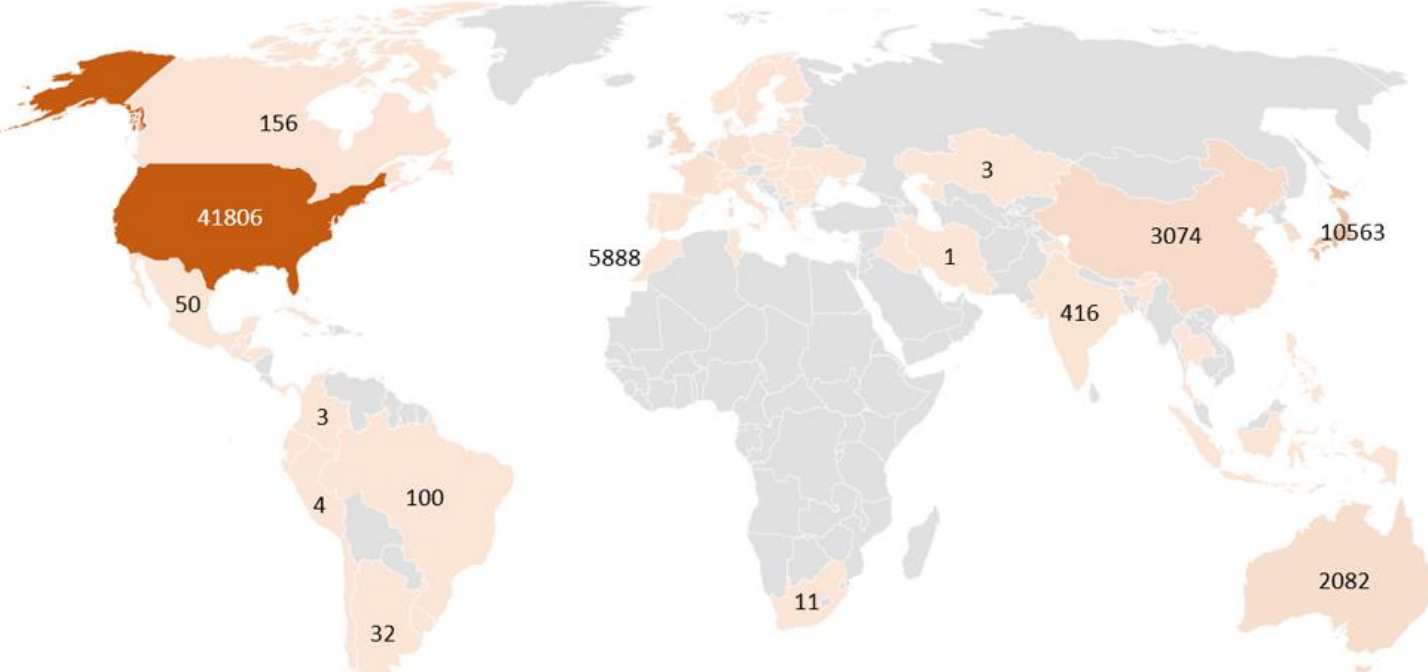

\begin{tabular}{|c|c|c|c|c|c|c|c|c|c|c|}
\hline \multicolumn{6}{|c|}{ US; 56\% } & JP; $14 \%$ & \multicolumn{2}{|c|}{$\mathrm{CN}$ GB } & 1 & \\
\hline
\end{tabular}

$B$ Company

HOFFMANN LA ROCHE \& CO AG F

GENENTECH INC

SANOFISA

CHUGAI SEIYAKU KK

REGENERON PHARM INC

NOVARTIS AG

MEDIMMUNE LLC

ABBOTT GMBH\&CO KG

AMGEN INC

BIOGEN MA INC

WYETH LLC

GLAXOSMITHKLINE BIOLOGICALS SA

ABBVIE INC

MERCK \& CO INC

PFIZER INC

US DEPT HEALTH \& HUMAN SERVICES

CENTOCOR ORTHO BIOTECH INC

UNIV CALIFORNIA

KYOWA HAKKO KIRIN CO LTD

MEDAREXINC

\begin{tabular}{|c|c|c|c|c|c|c|c|c|c|c|}
\hline \multirow[b]{2}{*}{2007} & \multicolumn{9}{|c|}{ Earliest Priority Year } & \multirow[b]{2}{*}{ Total } \\
\hline & 2009 & 2008 & 2006 & 2010 & 2011 & 2012 & 2013 & 2014 & 2015 & \\
\hline & & & & & & & & & & 3.648 \\
\hline & & & & & & & & & 0 & 2.098 \\
\hline & & & & & & & & - & - & 1.346 \\
\hline & & & & & & & & 0 & ○ & 1.215 \\
\hline & 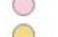 & & & & & & & $\bigcirc$ & $\circ$ & 1.087 \\
\hline & & & & & & & & & 0 & 1.019 \\
\hline & 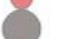 & & & & 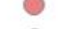 & & & 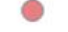 & $\bullet$ & 891 \\
\hline & & & & & 0 & $\dot{0}$ & $\dot{\theta}$ & & & 819 \\
\hline & 0 & 0 & & 0 & 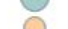 & 0 & 0 & 0 & 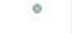 & 745 \\
\hline & 0 & & & 0 & 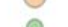 & & 0 & 。 & • & 741 \\
\hline & & & & 0 & 0 & 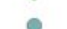 & . & & i & 721 \\
\hline - & & & - & 0 & ? & • & - & $\bullet$ & - & 580 \\
\hline & O & 0 & ? & - & $\bullet$ & $\bullet$ & - & - & $\bullet$ & 574 \\
\hline • & - & - & • & • & 궁 & • & • & • & - & 370 \\
\hline ○ & 0 & 0 & 0 & 0 & ○ & • & 0 & 0 & 。 & 358 \\
\hline O & $\circ$ & O & O & $\odot$ & $\circ$ & & . & . & & 326 \\
\hline 0 & O & ○ & $\circ$ & $\bullet$ & 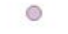 & 0 & ○ & $\circ$ & $\circ$ & 325 \\
\hline O & 0 & ○ & 0 & $\bullet$ & - & $\circ$ & & $\circ$ & • & 252 \\
\hline - & - & () & O & & . & & & & & 197 \\
\hline
\end{tabular}

Figure 2: A) World map of the patent families' distribution according to the priority country. The graph line represents the percentage of the patent counts of each country or office relative to the total. B) Bubble chart representing the top 20 assignees and its evolution from 2007 to 2015 (the last two years were not shown since the number of patents is decreased because of the publication window of 18 months)

\subsection{Factors contributing to the therapeutic mAbs success}

As mentioned previously, the intellectual property acts as a central pillar for the therapeutic mAbs market, along with the strength of the company to lead their discoveries from bench to market. Supporting this pillar, are the clinical implications and therapeutic properties of the drug itself.

In this manner, the success factors of a therapeutic mAbs comprehend three aspects. The attributes related to an efficient patent protection are very important to assure a sufficient return of investment on an environment of rapid technology change (Storz, 2011). Moreover, 
biosimilar has come to the market reducing the drug's cost and taking advantage of expired patents. Another relevant aspect is the attributes related to the company's strategies to develop the mAbs since failure on steps from the discovery to the market approval significantly impairs the drug's success. Among these multiple investments and strategies, an efficient R\&D expenditure and collaboration among companies mark the sector of biopharmaceuticals (Moorkens et al., 2017; Schuhmacher et al., 2016). Finally, the success of a therapeutic mAbs is also dependent on the aspects related to its medical relevance related to the clinical attributes of the therapy.

Thus, understanding which factors and key attributes related to them are more important for a novel mAbs being successful, will significantly assist the decision-making of a managerial sector of the biotech company. It has been reported that early decision-making reduces substantially the $R \& D$ costs by anticipating the trend of failure of a drug candidate (DiMasi et al., 2014). Decision-making methods such as HDM or Analytic Hierarchy Process (AHP) can serve as a proper alternative to analyze and quantify the factors that drive a therapeutic mAbs to success.

\subsection{Multi-criteria decision-making and its applications}

The HDM was created at the beginning of the 1980's by Kocaoglu (1983). It is a multi-criteria decision-making (MCDM) methodology very similar to Saaty's AHP (1980) with applications in multiple fields. HDM uses ration scale instead of eigen vectors in the case of AHP. In the case of HDM, the ratio scale used for judgment quantification method is the constant-sum method, which required experts to allocate 100 points between two decision variables at a time with respect to their relative importance to a higher level decision variable that they were associated with. Several recent studies demonstrated that use of constant sum method was more efficient in judgement quantification (Chan and Daim, 2018; Son and Sheikh, 2018)

The bulk of the method consists in depicting a problem or situation in a hierarchical manner. The model components, depth, and width will vary depending on each case, but usually, the first level represents the mission (i.e., the objective one is trying to achieve by building and applying the model) and the very last level represents the alternatives being considered to solve the problem and accomplish the mission. The levels in between first and last depict the attributes (criteria) related to the alternatives and that is important to the mission. 
The application of the model consists of gathering a pool of subject matter experts who will validate and quantify the model. Validation occurs when experts analyze and vet the components used in the model, attesting that those are relevant and enough to represent the issue in question. Quantification occurs when experts compare the model components against each other regarding their importance. The comparison, as it happens in AHP, is done in a pair-wise fashion and yields the importance of each model component with regards to the overall mission. After defining the importance of each component, the alternatives (last level) are evaluated concerning each component, and calculations are done in order to reach the conclusion of which of the alternatives is the best choice for the referred mission, considering the proposed criteria and their importance.

HDM and AHP are very well established decision-making techniques, having been used by researchers for several decades. Examples of researches applying both AHP and HDP are abundant in the literature. AHP has been shown to be an effective method to select healthcare-related improvement projects (Testik et al., 2017) and also to prioritize and select projects to invest using a variant form, named fuzzy-AHP (Shaygan and Testik, 2017). HDM has also been applied extensively and successfully in several areas. Estep (2015) utilized the methodology to evaluate R\&D project proposals, creating a technology transfer (TT) score that informs technology managers in the project selection phase. Daim et al. (2017) used HDM to assess robotics technologies in the power sector, coupling it with Technology Development Envelope (TDE) in order to have insights into the future of these technologies that are used to create strategic roadmaps. Researchers have also been experimenting with the methodology to tackle healthcare-related issues such as analyzing how electronic health records are adopted (Mudavadi et al., 2016) and to rank technology alternatives that have the potential to increase the diffusion of teleconsultation (Alanazi et al., 2015).

A few studies have been shown to apply MCDM in the biotechnology sector. Zahir (2002) used the AHP formulated in a Euclidian vector space to classify complex systems and objects in terms of its important attributes applied to the framework of plant genetics projects. Another study has made use of an AHP model to aid in the process of technology selection for a new product, in the context of a Chinese biotechnology firm (Zhang and Zhang, 2014). Wang et al (2013) have used the method to identify success factors in the adoption of ERP (Enterprise Resources Planning) systems for biotech companies and Chen and Wang (2010) analyzed biotech clusters using fuzzy AHP to produce academic and policy-making insights for the biotech sector. In a more straightforward application of the methodology, an AHPbased model for biotechnology firms were developed to select green suppliers for their 
operations (Nie, 2013). Although the decision methods have many applications, studies that combine these methods with technology assessment through patent scoring is still largely unexplored. The benefit of combining them would be leveraging expert judgement and technology intelligence data (patent scores) at the same time providing much better insight into technology assessment.

\subsection{Technology assessment and its association with decision-making models}

Technology assessment started out as an attempt, by the government, to evaluate technologies and the effect of those on people and on societal structures, most importantly the potential negative effects of it. Technology assessment studies would result in instructions and inputs for public institutions to design policies (Berg et al., 1976; Roessner and Frey, 1974; Van Den Ende et al., 1998; Watson, 1978; Wynne, 1975). Over time, and with the extinction of the Office of Technology Assessment - an Office created by the American Congress in the 1970 's - the positioning and purposes of technology assessment started to change. Private sector entities started to use the approach as a way to improve business performance. Instead of conducting technology assessment only to understand the effects of technology on society, they were aiming to understand the effects new technologies would have on their businesses, once developed and applied. In other words, organizations would conduct technology assessment studies to choose and control technologies (Azzone and Manzini, 2008), bringing benefits towards their businesses (Ahmad and Christakis, 1979).

The use of multi-criteria and multi-perspective approaches has been a constant in technology assessment. Since the inception of the TOP (Technical; Organizational; Personal) analysis (Linstone, 1999), multiple research has been done over the years using similar approaches. Several studies have used a hierarchical model to conduct health technology assessment with different purposes, such as to aid the design of a patient care database for low back pain (Hogaboam et al., 2014); to assess solar photovoltaic technologies under the STEEP analysis (Social; Technical; Economic; Environmental; Political) (Sheikh et al., 2011). Similarly, Sloane et al. (2003) built an Analytic Hierarchy Process model to assess different characteristics and choose from different options of neonatal ventilators for hospitals.

Patent data has also been used throughout the literature to aid technology assessment studies. Quintella et al. (2011) used both patents and scientific papers to map and assess the current state of development related to $\mathrm{CO} 2$ capture technologies. Dara and Sangamwar,(2014) used patent analysis to identify the most important new coming anticancer-related patents from Indian institutions and assessed those in terms of treatment and 
diagnosis, while also identifying areas for future research in the field. Trappey et al. (2014) looked at patent data and clinical reports to analyze the viability of new technology innovations in the field of dental implants. Daim et al (2006) combined patent analysis with other methods such as growth curves to forecast technologies including fuel cells, food safety and optical storage. Messeni Petruzzelli et al. (2015a) explored the influence of patents on other patents. Reitzig, (2004) developed a set of indicators for patent valuation for corporate purposes.

Patents were also associated with MCDM to assess technology value. Using AHP, Chiu and Chen (2007) developed a scoring system for patents from a licensor view highlighting important criteria (qualitative and quantitative) and their weights. They use four main dimensions for patent valuation: technology essence, cost dimension, product market, and technology market. Although the research proposed by these authors is the most closely related to what we have proposed in the present research, it does not consider specific factors related to the technology itself and aspects related to particularities of the companies, as in biotech. Therefore, our study establishes a MCDM consisting of 18 attributes sub-divided in three main factors concerning to the patent status, the profile of the company (ies) which holds the technology, and the medical relevance of the therapeutic mAbs, to determine an overall ES to a patent to predict its technology potential.

\section{RESEARCH FRAMEWORK}

\subsection{Selection of the factors and attributes to build the model}

The factors and attributes that contribute to the success of a therapeutic mAbs were selected based on information retrieved from the literature in scientific articles dealing with subjects such as intellectual property rights, the mAbs market and the clinical features of mAbs therapies. The factors, its identified attributes, and definitions were used as input to build the model into the HDM software for further analysis by the experts. The validated version of the hierarchical model and the references which support the attribute's choice is presented in the result section.

\subsection{Selection and description of the expert's panel}

To search for experts, we performed a keyword search on research foundations website to identify grants related to mAbs development. We also invited prominent researchers in the field identified by sources of scientific, technical, and medical research information such as ScienceDirect, PubMed, and Google Scholar. Some experts were invited via recommendation 
of medical principal investigators and researchers inside universities. The process of recruiting the subject matter experts was through snowball sampling or chain of referral.

A total of 20 experts agreed to participate. The panel was diverse since the subject of the factors have few knowledge overlaps. Some experts have both knowledge regarding two or more factors, and those were selected to analyze more than one factor according to their expertise. The experts chosen to be part of the study include 9 academic researchers, 6 of them in the field of innovation management and 3 in management of technology; 1 economist expert in patent valuation, 1 technology transfer office (TTO) agent, 1 university TTO vicecoordinator; $1 \mathrm{CEO}$ of a patent consultant firm; 2 IP consultant in a biotech company which develops mAbs; 1 a senior scientist and project manager at a biopharmaceutical company; 2 postdoctoral researchers in mAbs development; and 2 university PI in mAbs development. From this list, a total of 10 experts answered the questions related to the topic of patent status, 12 to the topic regarding the organization profile and 4 to the topic of medical relevance of mAbs. The model was submitted to the experts to perform the validation and subsequent pairwise comparison. Firstly, they quantified the importance of the three factors considering their relative importance in influencing the success of the mAb. Secondly, they quantified the model's attributes under each factor using the same approach described previously. Lastly, they judged the desirability functions.

\subsection{Model's validation and quantification}

Once the expert's panel has been defined, the model was then shown to them and their inputs were recorded. The first step of the model application, as aforementioned, is the validation. All experts consulted agreed (or not) that the components which compose the model are necessary and enough to describe the problem at hand and to influence the mission. Next, proceeding to the quantification, each expert compared every component in the second level against each other (in pairs) and every component of the third level against each other (again, in pairs), judging the importance of those components regarding the level above them. At the end of the process, the results of the expert's pairwise comparisons yielded the importance of each model component (in terms of percentage), regarding its parent level (local importance) and regarding the mission (global importance).

\subsection{Desirability Functions}

To determine the "score" of each patent and the final ranking of patents, desirability functions were used. Described and utilized jointly with HDM in several past studies (Estep, 2017; Gibson, 2016; Phan, 2013), desirability functions are a useful way of determining how 
desirable a certain characteristic or feature is. For each of the model components, levels describing different possibilities for each component were created and experts were asked to assign values from 0 (least desirable) to 100 (most desirable) to the levels. Those desirability values are then plotted to generate a desirability curve for each of the model's components. In turn, the desirability curves are contrasted with the characteristics of the patents, thus arriving at the value of each patent for each of the model components. If the patent had more than one assignee, the mean between the patent attribute's desirability level was used for the score. Then the values are multiplied by the model components' global importance and all partial score are summed up, hence the total score of that particular patent is obtained. The patents are then organized in a decreasing order regarding their scores, and the final patent ranking is generated.

\subsection{Selection of Patents}

The mAbs patents serve as alternatives in the model. To select the patents, we used the Integrity database from Clarivate Analytics which aggregates data from dugs which have an intention for further investment in clinical trials (usually indicated in the company's annual report) or have initiated the development of the drug candidate (any phase). In the database, we used a search query for mAbs drugs using the product type field option of "drugs and biologics" section, then we retrieved the patent list relative to each drug identified.

Subsequently, the patent list was filtered based on two main features. First, we defined the period concerning the patent priority year ranging the last five full years since the completion of the research (2013-2017). Second, we filtered the assignee country to US assignees-only or inventions originated from an institution unit based in the US. The detailed information from the patent list containing all the indicators using in this study were obtained from the Derwent Innovation database (Clarivate Analytics) by searching to the patent numbers and exporting the results on excel datasheet.

\subsection{Attribute's information retrieval from selected patents}

To retrieve information concerning the three criteria, we use three main databases. For patent data, we use the Derwent Innovation from Clarivate Analytics (Philadelphia - USA). For information related to the company's attributes, we take advantage of BCIQ module from BioCentury Publications Inc database (California - USA). For the medical, clinical relevance, and drug development report of the mAbs, we use information from the database Integrity also from Clarivate Analytics. Additionally, all molecules classified in the field on antibody mimetics including its essential information (targets, therapy, clinical phase stage and others) 
were exported from Integrity to assess the attribute of "competing technologies". Alternatively, we use information from CrunchBase (San Francisco) and Angellist (San Francisco) databases to get more detailed information from companies.

\section{RESULTS AND DISCUSSION}

\subsection{Factors and attributes which influence the therapeutic mAb success}

Our model's mission ( $1^{\text {st }}$ level of the model) is to determine a score to select the most promising inventions related to therapeutic mAbs. To achieve it, we have identified three main factors which contribute to the therapeutic mAbs to be considered promising $\left(2^{\text {nd }}\right.$ level of the model). Those are related to a proper patent protection and favorable status ("Patent Status"); the company's profile to advance on the development of the mAbs from the discovery to market ("Company/Assignee profile") and the medical relevance of the antibodies ("Medical Relevance"). Within each factor, we identified six attributes ( $3^{\text {rd }}$ level of the model) driving the importance of each factor to achieve our mission. In the next section, we describe each one of them and their associated attributes.

\subsubsection{Patent Status Factor:}

The market success of a therapeutic mAbs is strongly linked to an adequate patent protection, which involves a series of attributes. The first attribute we select is the patent independent claims. The subject-matter protected by the patent is legally conferred by the claims. The number of claims has extensively been used to assess the technology value of a patent (Jeong et al., 2016; Kim and Bae, 2017; Lee et al., 2007; Trappey et al., 2012). Each claim denoted an invention and consequently, the larger number of claims is directly correlated with the broader scope and usefulness of a patent. Another attribute included in the model is the patent citations, which have long been considered as a measure of impact and economic value of a technology (Carpenter et al., 1981; Narin et al., 1987). Patent citation links can also predicts emerging technologies (de Paulo and Porto, 2018; Pereira et al., 2018). We consider not only patent citation as well as Non-Patent Literature (NPL) citations since it is also an indicator of the value of a relevant technology (Callaert et al., 2006). The attributes related to the geographic coverage and expected life of a patent was considered, which represent the patent commercial scope and its term, respectively. The patent legal status was analyzed referring to the events during the lifetime of a patent such as patent abandonment, revocation for any reason and payments of maintenance fees. Assignees should proper protect and defend the patent maintenance to enjoy its benefits, if it is granted and active, it means that the owner expects some cash flows from the technology development (Serrano, 2010). 
The last attribute was the patent technological scope, which was suggested by the experts during the validation phase. The scope is represented by the number of different technological fields covered by the technology. A wider scope is an indicator of both the breadth and originality of an invention as well as more valuable knowledge (Fernández-Ribas, 2010; Lanjouw and Schankerman, 2001).

\subsubsection{Company/Assignee Profile Factor:}

For the attributes related to the companies that hold the patent, we identified six attributes as well. We consider the percentage of the revenue invested in R\&D that represents the R\&D intensity of a company to develop a therapeutic mAbs. The patent portfolio attribute is relevant for a company, not only as a result of an intense $R \& D$ activity but also for the value that can be extracted through the patent portfolio acting as knowledge stocks (Harlin and O'Connor, 2008). Another attribute is regarding the previously approved drugs by regulatory agencies, which denoted the company's strength to fully develop the drugs that will reach the market and available human resources with both scientific and legal aspects of drug development. The regulatory affairs of a company exert many functions including interacting with regulatory authorities, preparing documents for regulatory submission, developing regulatory strategies, and interacting with company staff (Moyer, 2006), and previous experience with these responsibilities will facilitate the path to the drug's approval. It has been shown that start-ups lack some capabilities from a big-biotech which has accumulated experience over the years, and also from limited financial resources (Pisano, 2006). Additionally, basic research developed in academia in some cases provides the initial intellectual property for a biotech company (Vallas et al., 2011). Due to these disparities among types of organization, we consider this attribute in our analysis. We also included two attributes related to cooperation, one dealing with technological cooperation measured by the patent co-ownership which impacts a patent value (Ma and Lee, 2008; Meyer, 2006) and another related to strategic alliances of the companies, a key success factor for biotechnology companies (Ernst \& Young, 2016; Moorkens et al., 2017).

\subsubsection{Medical Relevance Factor:}

This factor englobes attributes related to antibody clinical relevance and its therapeutic properties. The attribute "major condition to be treated" was considered in the model since there are differences in usefulness and applications of the therapy, such as cancer being the most prominent and dominant area (Geng et al., 2015). The attributes concerning the drug development status and the clinical phase represent the development status not considering 
the clinical stage, and the clinical phase itself, respectively. Both the development status, considering discontinuations, early phases, late phases and the clinical phase stage are important for a mAb success by overcoming the risks and difficulties which remains in this area. Some R\&D programs show difficulties to reach later stages, such as anti-infective and neuropharmacological indications, considered high-risk investments (Geng et al., 2015). Conversely, immune-checkpoint inhibitors have been successful in clinical with positives responses in patients (Sharma and Allison, 2015). Thus, the antibody cellular mechanism was also considered in the model. The antibody's type (chimeric, humanized, bispecific...) is also relevant due to the concerns of immunogenicity caused by fragments of mouse origins (Nelson et al., 2010). Some alternatives to antibodies, not belonging to the immunoglobulin family have been developed and it has already been tested in clinical trials threatening the stability of the mAbs market (Gebauer and Skerra, 2009; Storz et al., 2012). Thus, we add an attribute related to competing technologies, in order to consider the existence of alternatives to antibodies for the treatment of the same condition. Table 1 synthesizes the factors and attributes definition as well as the unit measure for each of them.

\section{Table 1}

Factor's and attribute's definitions and unit measure by each of them

\begin{tabular}{|c|c|c|}
\hline $\begin{array}{l}\text { Factors and } \\
\text { attributes }\end{array}$ & Definition and unit measured & Supported Refs. \\
\hline \multicolumn{3}{|l|}{ Patent's Attributes } \\
\hline $\begin{array}{l}\text { Patent Independent } \\
\text { Claims }\end{array}$ & Number of patent independent claims & $\begin{array}{l}\text { (Kim and Bae, 2017; Lee et } \\
\text { al., 2007; Trappey et al., 2012) }\end{array}$ \\
\hline Citations & $\begin{array}{l}\text { Number of the forward citation and scientific } \\
\text { references citations }\end{array}$ & $\begin{array}{l}\text { (Carpenter et al., 1981; Narin } \\
\text { et al., 1987) }\end{array}$ \\
\hline Geographic coverage & $\begin{array}{l}\text { Patent geographic coverage measured by the } \\
\text { number of INPADOC family members or by the } \\
\text { triad application (US, EP, WO) }\end{array}$ & $\begin{array}{l}\text { (Guellec and Van } \\
\text { Pottelsberghe De La Potterie, } \\
\text { 2000; Kim and Bae, 2017) }\end{array}$ \\
\hline Expected life & Years remaining for the "alive" patent & (Kim and Bae, 2017) \\
\hline Legal Status & $\begin{array}{l}\text { Is there any opposition/litigation? Is there any lack } \\
\text { of fee payment? Is the patent lapsed, annulled or } \\
\text { denied for any reason? }\end{array}$ & (Serrano, 2010) \\
\hline Patent Scope & $\begin{array}{l}\text { Number of 4-digit subclasses of the IPC the } \\
\text { invention is allocated to }\end{array}$ & $\begin{array}{l}\text { (Fernández-Ribas, 2010; } \\
\text { Lanjouw and Schankerman, } \\
\text { 2001) }\end{array}$ \\
\hline \multicolumn{3}{|l|}{ Assignee's Attributes } \\
\hline R\&D Expenditure & $\begin{array}{l}\text { What is the revenue percentage invested in } \mathrm{R} \& \mathrm{D} \text { by } \\
\text { the patent holder? Is there any venture or angel } \\
\text { capital? }\end{array}$ & $\begin{array}{l}\text { (Cozzens et al., 2005; DiMasi } \\
\text { et al., 2016) }\end{array}$ \\
\hline Patent Portfolio & Number of patents that the patent holder own & (Harlin and O’Connor, 2008) \\
\hline $\begin{array}{l}\text { Drugs approval by } \\
\text { regulatory agencies }\end{array}$ & $\begin{array}{l}\text { Number of previously approved drugs by regulatory } \\
\text { agencies. Are there any related to antibodies? }\end{array}$ & (Moyer, 2006) \\
\hline Organization Type & $\begin{array}{l}\text { Is the patent holder a start-up, a university, big } \\
\text { biotech, private company, government institution or } \\
\text { the patent is in cooperation? }\end{array}$ & $\begin{array}{l}\text { (Pisano, 2006; Vallas et al., } \\
\text { 2011) }\end{array}$ \\
\hline $\begin{array}{l}\text { Technological } \\
\text { Collaboration }\end{array}$ & $\begin{array}{l}\text { The rate of technological cooperation measure by } \\
\text { patent co-assignee frequency }\end{array}$ & $\begin{array}{l}\text { (Ma and Lee, 2008; Meyer, } \\
\text { 2006) }\end{array}$ \\
\hline
\end{tabular}




\begin{tabular}{|c|c|c|}
\hline Strategic alliances & $\begin{array}{l}\text { Measure by the intensity rate of contractual } \\
\text { agreements (franchising licensing and cross- } \\
\text { licensing), non-equity alliances (Joint R\&D, joint } \\
\text { product, long-term sourcing agreements) equity } \\
\text { alliances, joint venture, and merge/acquisitions }\end{array}$ & $\begin{array}{l}\text { (Ernst \& Young, 2016; } \\
\text { Moorkens et al., 2017) }\end{array}$ \\
\hline \multicolumn{3}{|c|}{ Medical Relevance attributes } \\
\hline $\begin{array}{l}\text { Major condition group } \\
\text { to be treated }\end{array}$ & $\begin{array}{l}\text { takes into consideration the relevance of the major } \\
\text { condition group (clinical condition) to be treated by } \\
\text { the therapeutic mAb, such as for cancer treatment, } \\
\text { Anti-infective therapy, treatment of inflammation and } \\
\text { hematological disorders, congenital malformations, or } \\
\text { rare disease }\end{array}$ & (Geng et al., 2015) \\
\hline $\begin{array}{l}\text { Drug Development } \\
\text { Status }\end{array}$ & $\begin{array}{l}\text { What is the stage of the drug development? } \\
\text { Discontinued or withdrawal, biological testing in the } \\
\text { laboratory only, pre-clinical or clinical, NDA, } \\
\text { registered or marketed? }\end{array}$ & $\begin{array}{l}\text { (Geng et al., 2015; Kaplon and } \\
\text { Reichert, 2018) }\end{array}$ \\
\hline Clinical Phase & the stage of the clinical phase & (Tsai and Erickson, 2006) \\
\hline $\begin{array}{l}\text { Antibody Cellular } \\
\text { Mechanism }\end{array}$ & $\begin{array}{l}\text { Does the cellular mechanism of action relevant to } \\
\text { the success of the antibody? The antibody acting as } \\
\text { anti-inflammatory molecule, viral entry inhibitor, } \\
\text { antimitotic and apoptosis inducer, angiogenesis } \\
\text { inhibitor, immune checkpoint inhibitors or signal } \\
\text { transduction modulators (targeting growth factors, } \\
\text { receptors...) will influence its success in the near } \\
\text { future? }\end{array}$ & $\begin{array}{l}\text { (Sharma and Allison, 2015; } \\
\text { Topalian et al., 2015) }\end{array}$ \\
\hline Antibody Category & $\begin{array}{l}\text { Is the type of antibody relevant to the success of the } \\
\text { molecule? Is it a human mAb, or humanized, } \\
\text { chimeric, bispecific, scFv, murine or recombinant } \\
\text { mAb? }\end{array}$ & (Nelson et al., 2010) \\
\hline $\begin{array}{l}\text { Existence of } \\
\text { Competing } \\
\text { Technologies }\end{array}$ & $\begin{array}{l}\text { Factors related to the existence of any alternative to } \\
\text { antibodies for the treatment of the same condition } \\
\text { such as antibody mimetics targeting the same } \\
\text { molecule? }\end{array}$ & $\begin{array}{l}\text { (Gebauer and Skerra, 2009; } \\
\text { Storz, 2011) }\end{array}$ \\
\hline
\end{tabular}

All factors and attributes along with its definitions were used to build the model to show to the expert panel for further validation and quantification. A previous version of the model was sent to the experts for validation and some minor modifications were suggested to reach the final version (Figure 3). Most experts suggested changes on the first version of the attribute "Patent Claims" to the "Patent Independent Claims", and to insert a new attribute named "Patent Scope" to the "Patent Status" factor. In the "Company/Assignee Profile" factor, the experts suggested splitting the formerly technological collaboration into "Technological collaboration" and "Strategic alliances". In the "Medical Relevance" factor, the experts suggested adding the attribute "Competing Technologies". 


\begin{tabular}{|c|c|c|}
\hline \multicolumn{3}{|c|}{$\begin{array}{c}\text { Determine a score to select the most promising inventions related } \\
\text { to therapeutic monoclonal antibodies }\end{array}$} \\
\hline Patent Status & Company's profile & Medical Relevance \\
\hline $\begin{array}{l}\text { Patent independent } \\
\text { claims }\end{array}$ & $R \& D$ expenditure & $\begin{array}{l}\text { Major condition } \\
\text { group to be treated }\end{array}$ \\
\hline Citations & Patent portfolio & $\begin{array}{l}\text { Drug development } \\
\text { status }\end{array}$ \\
\hline $\begin{array}{l}\text { Geographic } \\
\text { coverage }\end{array}$ & $\begin{array}{l}\text { Drugs approval by } \\
\text { regulatory agencies }\end{array}$ & Clinical phase \\
\hline $\begin{array}{l}\text { Expected life of a } \\
\text { patent }\end{array}$ & Organization type & $\begin{array}{l}\text { Antibody cellular } \\
\text { mechanism }\end{array}$ \\
\hline Legal status & $\begin{array}{l}\text { Technological } \\
\text { collaboration }\end{array}$ & $\begin{array}{l}\text { Antibody } \\
\text { category/type }\end{array}$ \\
\hline Patent scope & Strategic alliances & $\begin{array}{l}\text { Competing } \\
\text { technologies }\end{array}$ \\
\hline
\end{tabular}

Figure 3: The HDM model designed to determine an emerging technology score for therapeutic mAbs. Texts in red and orange boxes show modifications on the first version of the model suggested by the expert panel.

\subsection{The relative importance of the factors and attributes which influence the} therapeutic $m A$ bs success

We took advantage of a HDM to quantify the relative importance of factors and attributes to build the ES parameters, considered as a ranking/rating patent valuation method (Razgaitis, 1999). After the submission of the model to the expert panels for the quantification of the first level, we performed the calculation of the importance score of each factor for the mission achievement. The experts should be able to answer which factor is most important for a $\mathrm{mAb}$ to become relevant in the future. The results reliability was obtained by controlling for inconsistency and disagreement. Leveraging metrics utilized in previous research (Estep, 2017; Gibson, 2016; Phan, 2013), the inconsistency level was calculated for each expert, the disagreement level was calculated for each panel, and the acceptable threshold for both individual inconsistency and group disagreement was 0.1 (10\%). Since, throughout the whole model application, inconsistency and disagreement levels were below the threshold, no corrective actions had to be taken. The properties of a therapeutic mAb have been long described as the most relevant to their usefulness (Clark, 1986) and the results showed that attributes related to the "Medical Relevance" contribute $50 \%$ for a mAbs to be considered promising. The attributes related to patent and the organization contributes $29 \%$ and $21 \%$ respectively (Figure 4).

\begin{tabular}{|l|c|c|c|}
\hline & Patent Status & Company/Assignee profile & Medical Relevance \\
\hline Mean & 0.29 & 0.21 & 0.5 \\
\hline
\end{tabular}




\begin{tabular}{|l|c|c|c|}
\hline Minimum & 0.14 & 0.11 & 0.28 \\
\hline Maximum & 0.58 & 0.53 & 0.67 \\
\hline SD & 0.12 & 0.1 & 0.11 \\
\hline Disagreement & \multicolumn{3}{|c|}{0.096} \\
\hline
\end{tabular}

Figure 4: Expert's quantification relative to the model's first level.

The next step was submitting the model's second level, the factors' attributes, to experts perform the quantifications. At this step, the experts should be able to define a rate of importance to each attribute through pair-wise comparisons. Briefly, the results showed that in the "Patent Status" factor, the top three most important attributes are the patent scope and geographic coverage, both contributing $21 \%$, followed by the patent citations, which contribute $16 \%$ to the factor. Similar to what we found, the commercial scope measured by the geographic coverage based on the number of patent members has been reported by another studies as an indicator of the economic value of a patent (Guellec and Van Pottelsberghe De La Potterie, 2000). Thus, protecting a mAb patent in multiple countries is a key attribute for a therapy to be considered emerging.

As for the "Company/Assignee profile" factor, the attributes related to the preexistence of drugs approved by regulatory agencies contributes $23 \%$ to the factor's importance, followed by the presence of strategic alliances and the R\&D expenditure, with $20 \%$ and $18 \%$ respectively. The investment in a biopharmaceutical approval is very costly and reflects the company's robustness to lead a candidate to the market (Tsai and Erickson, 2006). Thus, previously approved drugs by regulatory agencies demonstrates not only the company's commitment to leading a candidate to the late stages of clinical studies, but also reinforces the importance of the company's expertise in meeting all requirements to approve a new drug usually led by the regulatory affairs.

The most important attributes related to the "Medical Relevance" factor according to our model, is the drug's clinical phase that contributes $21 \%$ of the factor importance, followed by the mAb mechanism of action (19\%) and the clinical condition to be treated by the mAb (18\%) (Figure 5). The mAb clinical phase stage represents a crucial step since lack of drug's efficiency and safety tests as well as insufficient cash to lead the trials can absolutely restrict the biopharmaceutic to reach the market (Tsai and Erickson, 2006).

\begin{tabular}{|l|c|c|c|c|c|c|}
\hline Patent status & $\begin{array}{c}\text { Patent } \\
\text { Independen } \\
\text { t Claims }\end{array}$ & Citations & $\begin{array}{c}\text { Geographic } \\
\text { coverage }\end{array}$ & $\begin{array}{c}\text { Expected } \\
\text { life }\end{array}$ & Legal Status & Patent Scope \\
\hline Mean & $\mathbf{0 . 1 2}$ & $\mathbf{0 . 1 6}$ & $\mathbf{0 . 2 1}$ & $\mathbf{0 . 1 5}$ & $\mathbf{0 . 1 6}$ & $\mathbf{0 . 2 1}$ \\
\hline Minimum & 0.08 & 0.01 & 0.13 & 0.08 & 0.06 & 0.07 \\
\hline Maximum & 0.2 & 0.38 & 0.35 & 0.2 & 0.26 & 0.47 \\
\hline Std. Deviation & 0.06 & 0.1 & 0.07 & 0.04 & 0.05 & 0.12 \\
\hline
\end{tabular}




\begin{tabular}{|c|c|c|c|c|c|c|}
\hline Disagreement & \multicolumn{6}{|c|}{0.071} \\
\hline $\begin{array}{c}\text { Organization } \\
\text { profile }\end{array}$ & $\begin{array}{c}\text { R\&D } \\
\text { Expenditure }\end{array}$ & $\begin{array}{c}\text { Patent } \\
\text { Portfolio }\end{array}$ & $\begin{array}{c}\text { Drugs } \\
\text { approved }\end{array}$ & Org. Type & $\begin{array}{c}\text { Tech. } \\
\text { Collaboration }\end{array}$ & $\begin{array}{l}\text { Strategic } \\
\text { alliances }\end{array}$ \\
\hline Mean & 0.18 & 0.15 & 0.23 & 0.1 & 0.15 & 0.2 \\
\hline Minimum & 0.04 & 0.04 & 0.06 & 0.02 & 0.05 & 0.08 \\
\hline Maximum & 0.34 & 0.22 & 0.46 & 0.17 & 0.22 & 0.5 \\
\hline Std. Deviation & 0.09 & 0.05 & 0.14 & 0.05 & 0.06 & 0.11 \\
\hline Disagreement & \multicolumn{6}{|c|}{0.081} \\
\hline $\begin{array}{c}\text { Medical } \\
\text { Relevance }\end{array}$ & $\begin{array}{c}\text { Major } \\
\text { condition to } \\
\text { be treated }\end{array}$ & $\begin{array}{l}\text { Drug Dev. } \\
\text { Status }\end{array}$ & $\begin{array}{l}\text { Clinical } \\
\text { Phase }\end{array}$ & $\begin{array}{c}\text { Antibody } \\
\text { Cellular } \\
\text { Mechanism } \\
\end{array}$ & $\begin{array}{l}\text { Antibody } \\
\text { Category }\end{array}$ & $\begin{array}{c}\text { Competing } \\
\text { Techs. }\end{array}$ \\
\hline Mean & 0.18 & $\mathbf{0 . 1 7}$ & 0.21 & 0.19 & 0.13 & 0.12 \\
\hline Minimum & 0.1 & 0.12 & 0.15 & 0.17 & 0.11 & 0.1 \\
\hline Maximum & 0.28 & 0.22 & 0.29 & 0.21 & 0.16 & 0.15 \\
\hline Std. Deviation & 0.07 & 0.04 & 0.06 & 0.02 & 0.02 & 0.02 \\
\hline Disagreement & \multicolumn{6}{|c|}{0.043} \\
\hline
\end{tabular}

Figure 5. The model's 2nd level quantification results based on expert's opinions of the six attributes of each factor considered in the study.

Overall, among the 18 attributes analyzed in this study, the most important that contributes to a therapeutic mAb to be successful it's the mAb clinical phase stage, accounting for $10 \%$ of the antibody's ES (Figure 6). The results indicated that progress into later stages of clinical phase will likely lead to mAb success. Following the importance rate for the ES determination, the antibody mechanism of action is the second and the clinical condition to be treated by the mAbs the third most important attributes for the ES, contributing $9.5 \%$ and $9 \%$ to the model's mission, respectively. For the whole model, the attribute with the least importance is the organization type, contributing only $2 \%$. Despite the attributes relative to patents being fairly discussed as impacting a patent value, those associated to the biopharmaceutical company and the medical relevance of the antibodies through their relative importance identified in this study are unprecedent in the literature and depict what matters for a mAbs development to be successful. 


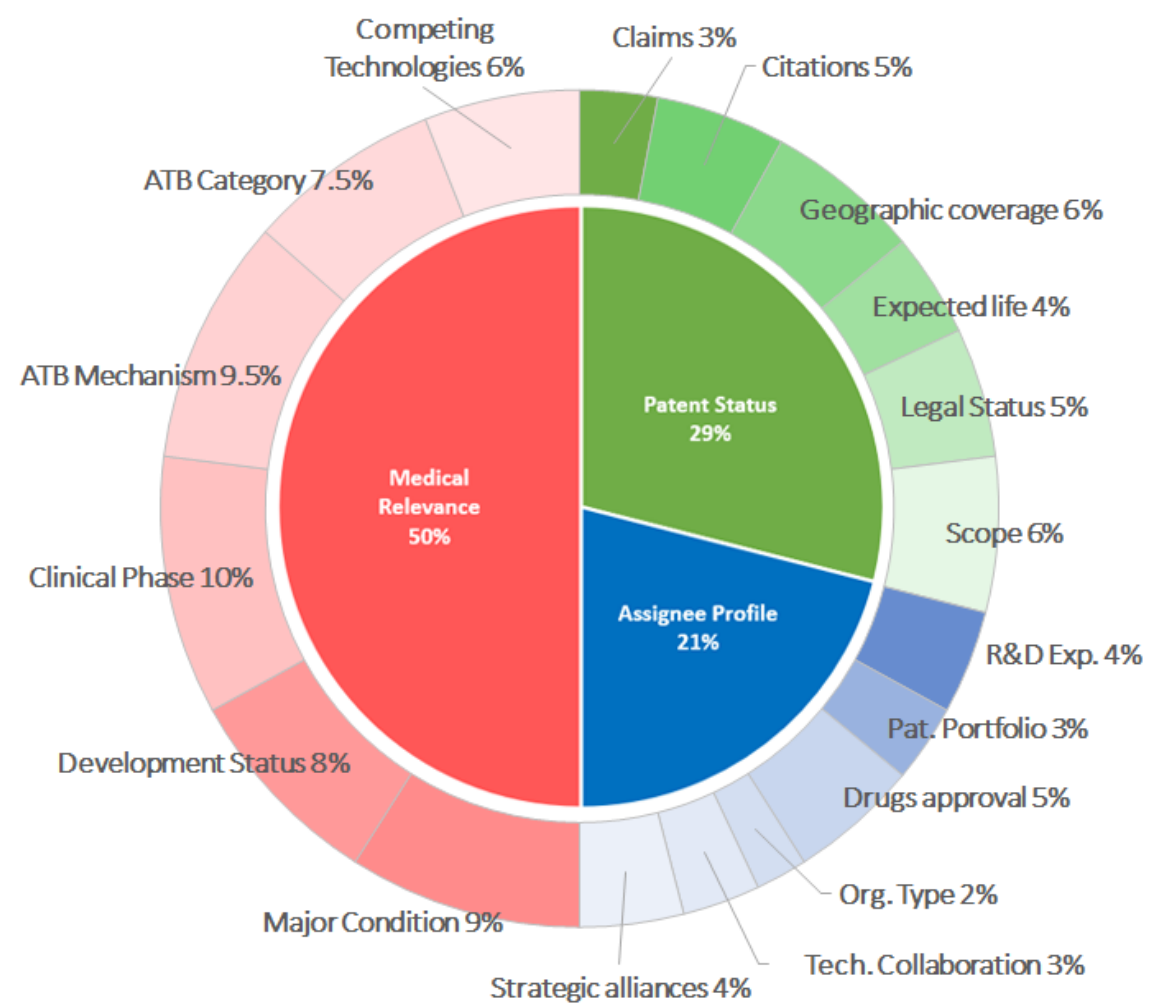

Figure 6: The overall importance of the 18 attributes to achieve the model's mission based on expert's opinion.

\subsection{The desirability levels for the attributes}

The next step was the quantification of the desirability curves by the experts allowing the judgment of whatever alternatives (patents) based on the desirability levels of each attribute. The higher the value of the desirability level the most desirable is the attribute to achieve its full importance (e.g. if drug clinical phase is relevant on a percentage of $10 \%$ to accomplish the mission, the experts will rank the desirability score of all levels such as preclinical, phase I, phase II, Phase III or an already launched reaching the highest, lowest and intermediate desirability level). The experts quantified a total of 105 different levels distributed by the 18 attributes. The results were aimed to provide instructions to designate a score for each attribute according to the patent features, to finally consolidate the final ES for each patent.

The desirability levels were based on the attribute meaning in which the least desirable, most desirable and levels in between were identified and quantified by the experts. For the patent factor, the most desirable level for a patent to be considered emerging is to contain more than 20 independent claims in the document (Fig. 7A), more than two citing patents (Fig. 7B), a broader geographic coverage with US, EP and WO applications (Fig. 7C), more than 15 valid years remaining (Fig. 7D), a patent which was granted or under analysis (for any patent family member) (Fig. 7E), and with a wider scope consisting of 3 or more IPC 
4-digit subclasses (Fig. 7E). A perfect patent for our model will be the one which fulfills the highest desirability level.

A

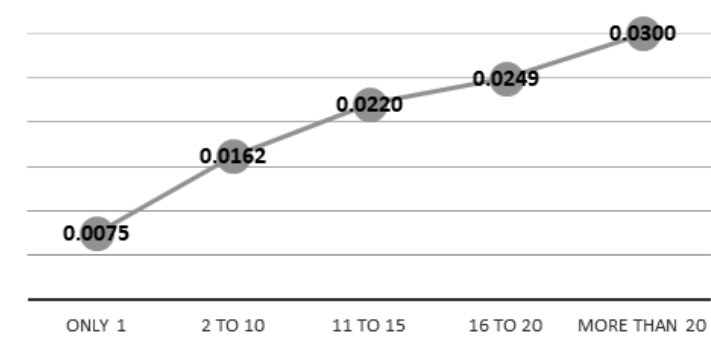

C

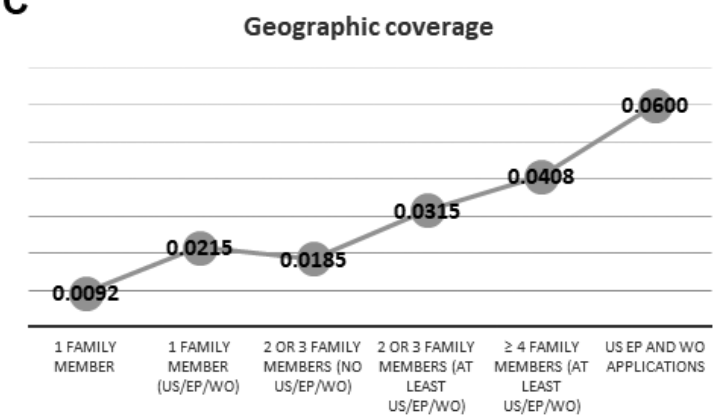

E

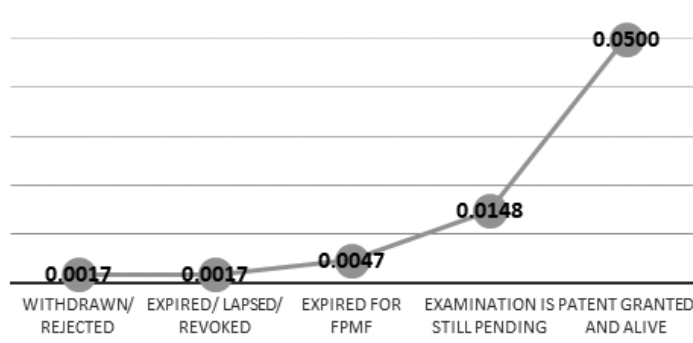

B Citations

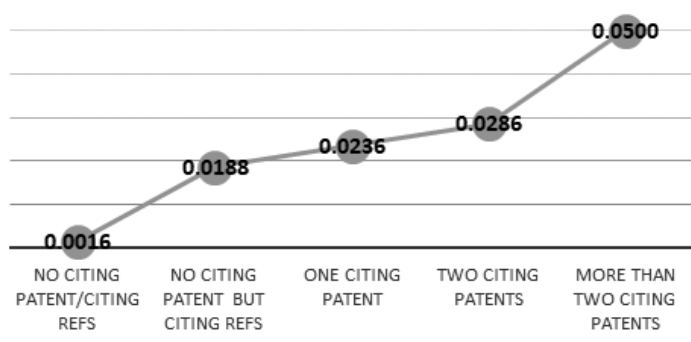

D

Patent Life

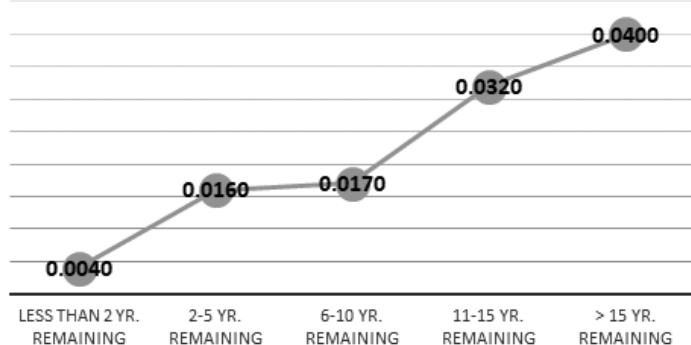

$\mathbf{F}$

Patent Scope

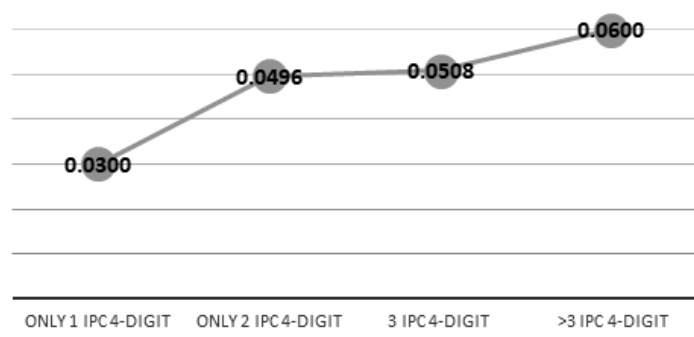

Figure 7: Desirability curves for the six attributes related to the "Patent Status" factor

For the desirability levels concerning the assignee profile, we noted some interesting findings. The most desirable level for the company to spend on $R \& D$ as a percentage of the revenue was between $15 \%$ to $20 \%$, and, more than that is less desirable for a company to develop a successful mAbs biologic (Fig. 8A). Another interesting finding is the type of assignee. We observed that the most desirable level to achieve a promising patent is the coassignment of the patent as a result of cooperation among other assignees (such as Universities, research institutes or another company), which is more desirable than the patent holder being a big biotech company (Fig 8D). The importance of cooperation was also highlighted through the desirable levels of technological cooperation and strategic alliances (Fig 8F). Joint venture and equity alliances such as merge and acquisitions are more desirable 
than non-equity alliances, such as licensing, franchising, joint $R \& D$, and some contractual agreements. The desirability level of the six attributes from the assignee profile factor is shown in figure $8 \mathrm{~A}-\mathrm{F}$.

A

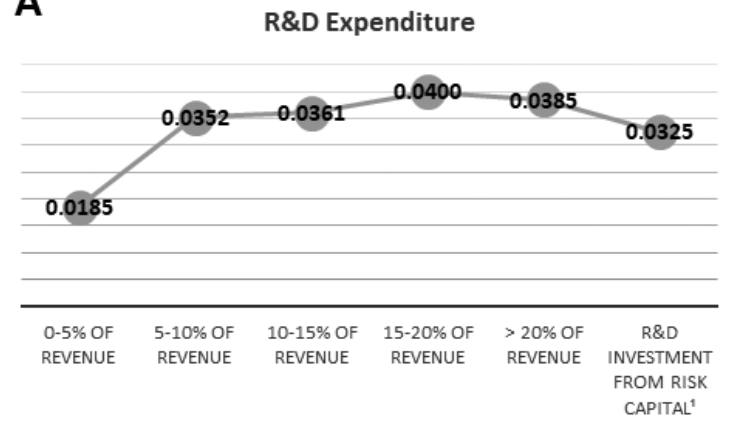

C

Approved drugs

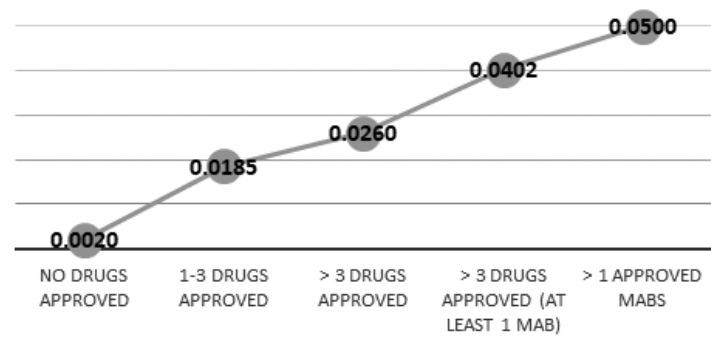

E

Technological Cooperation

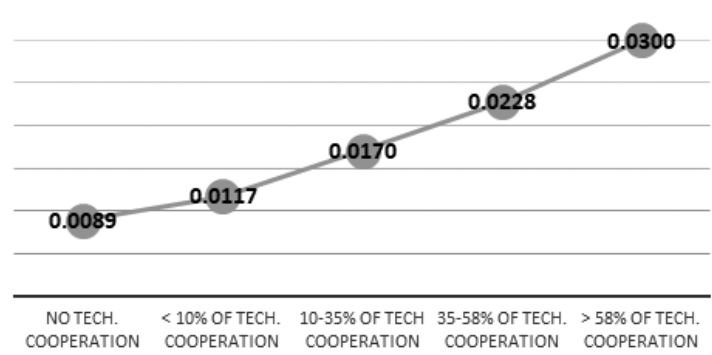

B

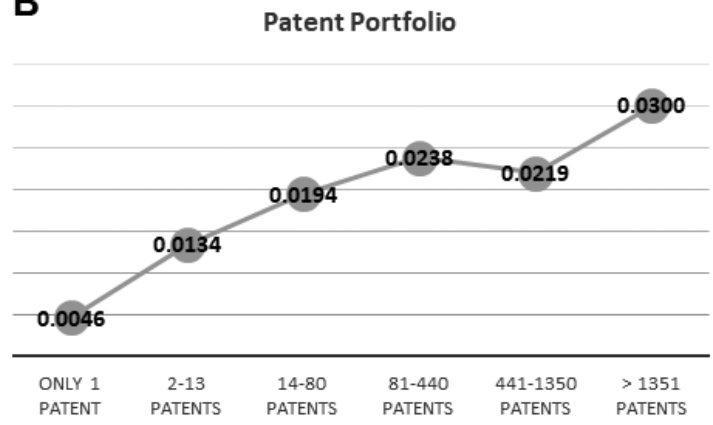

D

Assignee Type

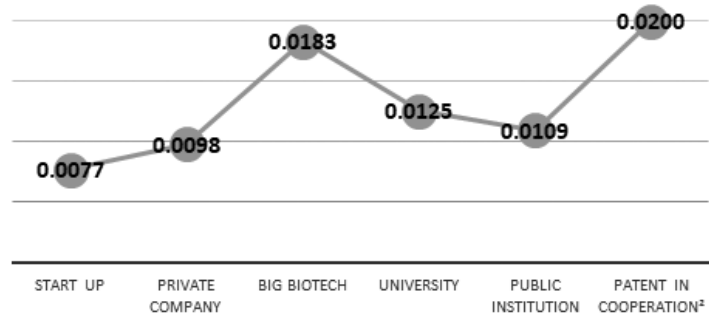

$\mathbf{F}$ Strategic Alliances

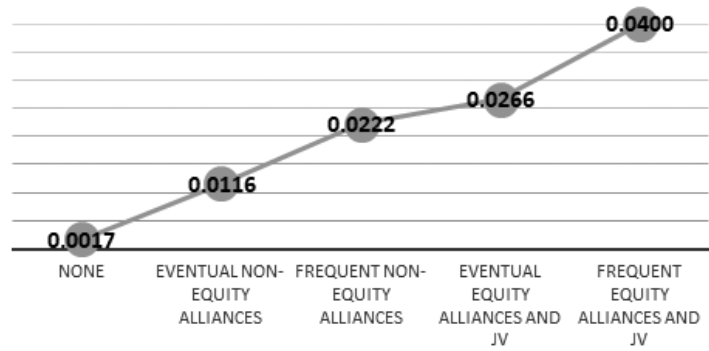

Figure 8: Desirability curves for the six attributes related to the "Assignee profile" factor. ${ }^{1}$ Universities were included in the group. ${ }^{2}$ The level was dependent on a patent being analyzed.

The medical relevance is the factor which aggregates the highest number of levels, 39 levels at total, and some interesting conclusions must be highlighted. The therapeutic mAbs developed to treat cancer are the ones which received the most desirable level among the major condition group attribute (Fig. 9A). Drugs at the biological testing stage got only 25\% of the attribute's importance relative to the drug's stage attribute (Fig. 9B). Antibodies inhibiting the immune checkpoint proteins are the most desirable concerning the mechanism of action (Fig. 9D). Chimeric antibodies are not only less desirable than murine monoclonal 
antibodies, and human and humanized monoclonal antibodies are the most desirable (Fig. 9E). The desirability levels for the medical relevance attributes is shown in figure 9 A-F.

A

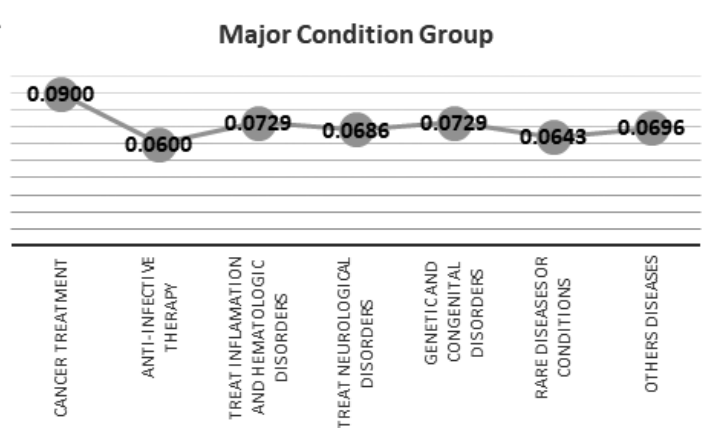

C

Clinical Phase

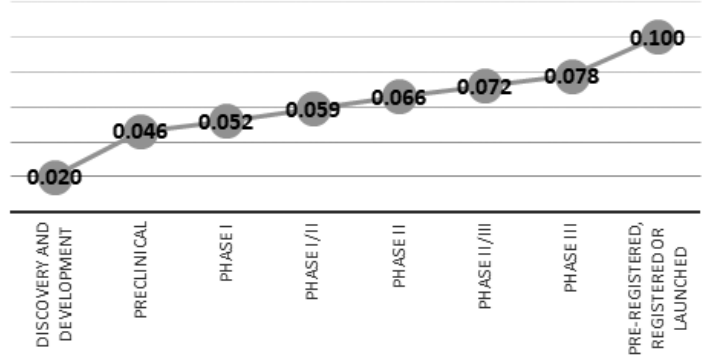

E

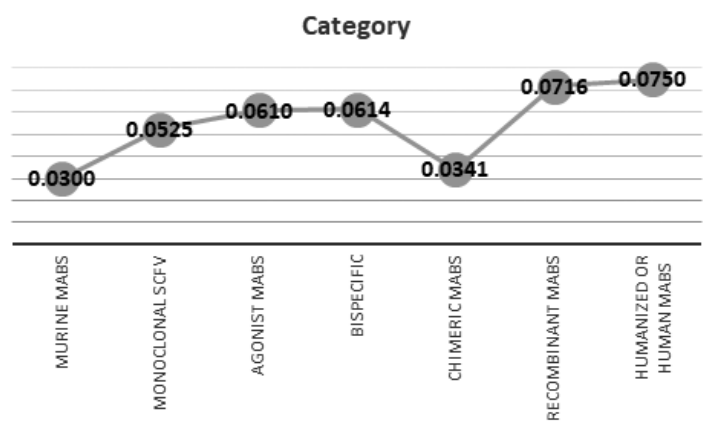

B

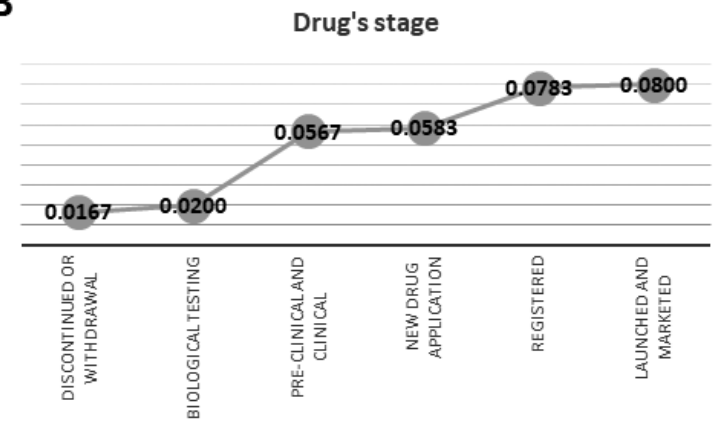

D

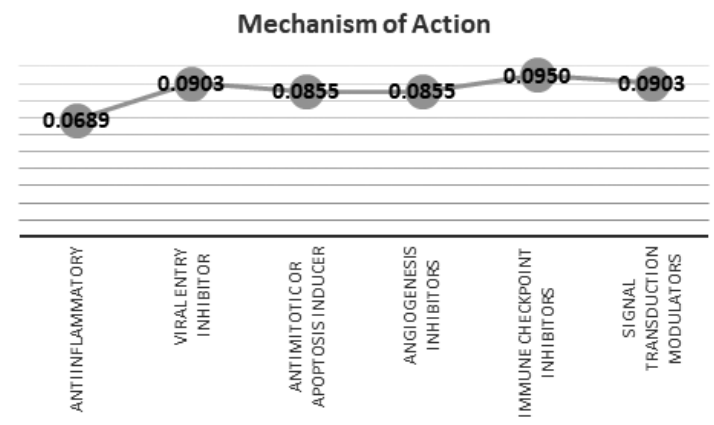

$\mathbf{F}$ Competing Technologies (CT)

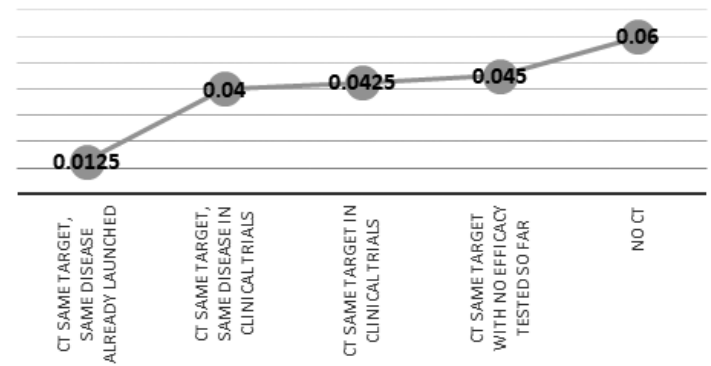

Figure 9: Desirability curves for the six attributes related to the "Medical Relevance" factor

\subsection{Inferring the emerging score for a pool of therapeutic mAbs patents}

The next step of the research was to apply the model to a pool of patents related to therapeutic monoclonal antibodies, to identify those with the highest ES. As mentioned before, the US is the country with the largest biotech market and where more than a half of the inventions were originated. Thus, we selected lead compound and drugs under active development which has at least one US company as the patent holder by combining searches on Integrity and Derwent Innovation, both from Clarivate Analytics. Moreover, we define a temporal range consisting of recent inventions with the priority year between 2013 and 2017 . In total, 1053 INPADOCs (International Patent Documentation), from 402 companies resulting in 709 drugs and biologics were selected as alternatives for further ranking. The 
fundamental tool that allowed us to analyze such a large number of patents is the desirability functions. And, to the best of our knowledge, this is the first study that analyzed such a high number of alternatives (patents).

To infer a score for each of the 18 attributes, we judge every unit measured from patents according to its desirability levels. The scores of the attributes score from patent status, assignee profile and medical relevance factors were integrated for each of the 1053 patents. Figure 10 shows the distribution score of the three factors for each patent. The green dots represent patents adjusted by the patent status score (max 0.29), blue dots represent the assignee profile score and red dots the medical relevance score. For the patent assignee score, the minimum score identified was 0.1506 and the maximum 0.2820 (average 0.2073 ); for the assignee profile score, the minimum was 0.0309 and maximum 0.2029 (average 0.1386) and for the medical relevance score, the minimum was 0.2499 and the maximum 0.4855 (average 0.3939).

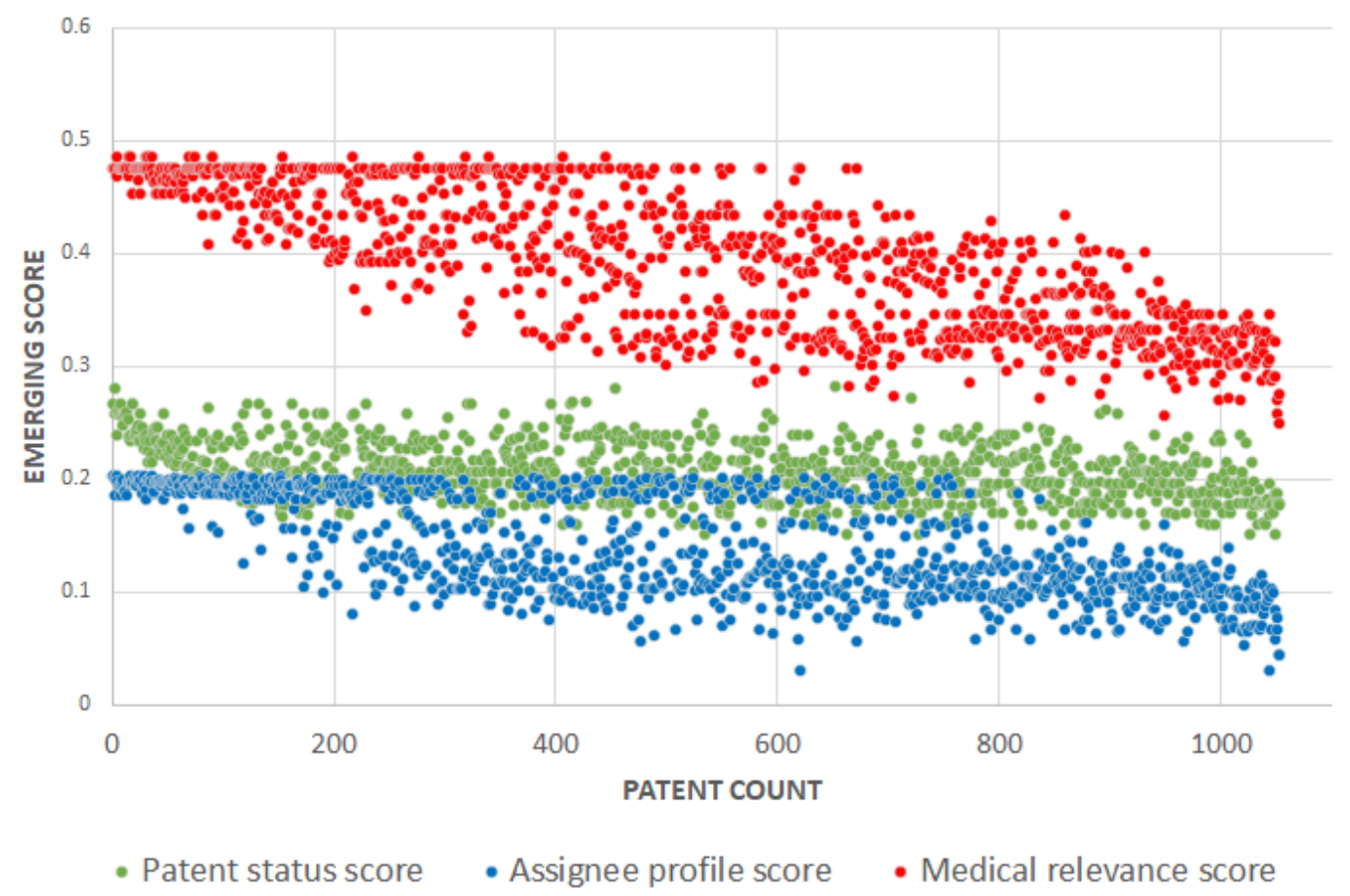

Figure 10: Distribution of the patent score for each of the three factors analyzed.

The total score for each patent was then calculated by the sum of the three factors score. A "perfect" patent in our model should be able to fill the highest desirability levels in all 18 attributes, reaching a score of 1 . In our analysis, the maximum score found was 0.9436 , which means that it misses only $5.6 \%$ of all factors combined. The minimum score was 0.4711, which means that this patent has the less potential to be considered emerging according to factors and attributes analyzed by the study. The average of the total ES was 
0.7398 , a reasonable score for a technology emergence. The distribution of the total score is shown in figure 11.

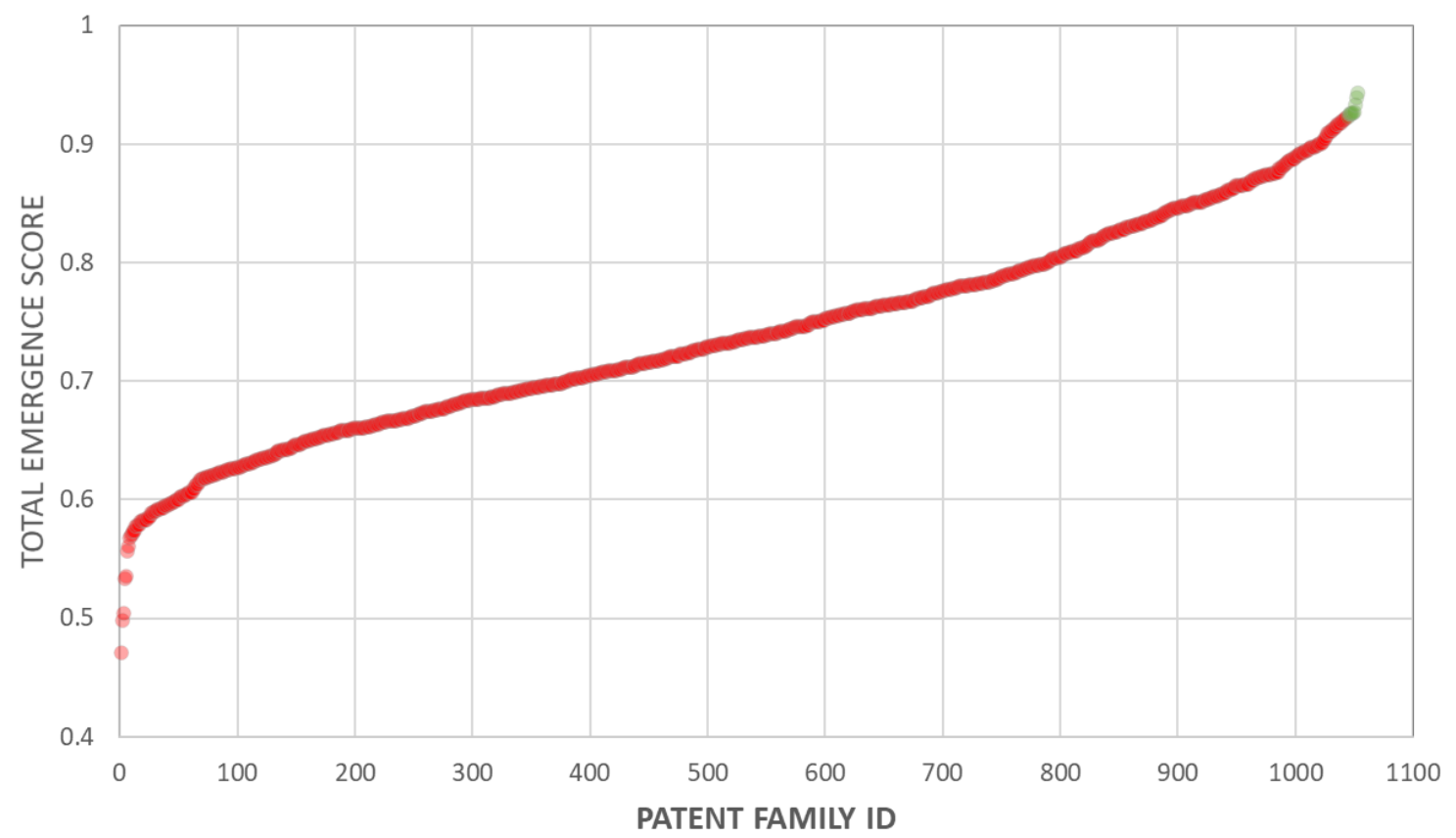

Figure 11: Distribution of total score for the 1053 patents analyzed (dots). Green dots represent the top 10 patents with highest ES.

Patents included the top 10 according to the ES, highlighted in green at figure 11, bring some interesting information concerning the therapeutic mAbs (Table 2). From the list of 10 highest scored patents, nine have indications to treat cancer and one to treat asthma (US20150044204A1). Furthermore, nine of the ten deals with combination therapies instead of monotherapy of a therapeutic mAbs and eight has the PD-1 protein or its ligand PD-L1 as a target of the mAb. Based on the features of the ten patents with the highest ES, we can generalize that the emerging technology for therapeutic mAbs is combination therapies of mAbs usually against PD-1 or PD-L1 aiming to boost the immune system to kill cancer cells. The biopharmaceutical Bristol Myers Squib owns three of the 10 patents with highest ES. Other players among the group are Merck \& Company, Novartis (US unit) and Pfizer with two patents (as co-assignee or not) each.

Table 2

The list of the top 10 patents with highest ES

\begin{tabular}{|c|c|c|c|}
\hline $\mathbf{E S}$ & Pub. Number & mAb therapy description & Assignee(s) \\
\hline 0.9436 & $\begin{array}{l}\text { WO2015119923A1 } \\
(2014)\end{array}$ & $\begin{array}{l}\text { Combination of Anti-PD-1 + Agonist of 4-1BB (a } \\
\text { co-stimulatory immune checkpoint molecule) }\end{array}$ & $\begin{array}{l}\text { Merck \& Company } \\
\text { | Pfizer INC }\end{array}$ \\
\hline 0.9399 & $\begin{array}{l}\text { WO2016100882A1 } \\
(2014)\end{array}$ & $\begin{array}{l}\text { Combination of Anti-PD-1 (PD-L1, CTLA4, LAG3) } \\
+ \text { Second Therapeutic Agent }\end{array}$ & Novartis \\
\hline 0.9336 & $\begin{array}{l}\text { WO2015026634A1 } \\
(2013)\end{array}$ & $\begin{array}{l}\text { Combination of Anti-PD-1 + dinaciclib (CDK } \\
\text { inhibitor) }\end{array}$ & Merck \& Company \\
\hline
\end{tabular}




\begin{tabular}{llll}
\hline 0.9277 & $\begin{array}{l}\text { WO2015179236A1 } \\
(2014)\end{array}$ & $\begin{array}{l}\text { Combination of Anti-CCR4 + Agonist of 4-1BB (a } \\
\text { co-stimulatory immune checkpoint molecule) }\end{array}$ & $\begin{array}{l}\text { Kyowa Hakko } \\
\text { Kirin |Pfizer INC }\end{array}$ \\
\hline 0.9267 & $\begin{array}{l}\text { US20150044204A1 } \\
(2013)\end{array}$ & Effective amount of Anti-CD125 & $\begin{array}{l}\text { Astrazeneca } \\
\text { Medimmune INC }\end{array}$ \\
\hline 0.9263 & $\begin{array}{l}\text { WO2015042246A1 } \\
(2013)\end{array}$ & Combination of Anti-PD-1 + Anti-LAG-3 & $\begin{array}{l}\text { Bristol-Myers } \\
\text { Squibb }\end{array}$ \\
\hline 0.9261 & $\begin{array}{l}\text { WO2016040892A1 } \\
(2014)\end{array}$ & $\begin{array}{l}\text { Combination of Anti-PD-1 (or PD-L1) + c-MET or } \\
\text { CDK4/6 or PI3K or BRAF or FGFR or MEK or }\end{array}$ & Novartis \\
& & BCR-ABL inhibitor & \\
\hline 0.9256 & $\begin{array}{l}\text { WO2015134605A1 } \\
(2014)\end{array}$ & $\begin{array}{l}\text { Combination of Anti-PD-L1 + Anti-angiogenic } \\
\text { tyrosine kinase inhibitor or an anti-CTLA-4 }\end{array}$ & $\begin{array}{l}\text { Bristol-Myers } \\
\text { Squibb }\end{array}$ \\
\hline 0.9256 & $\begin{array}{l}\text { WO2015176033A1 } \\
(2014)\end{array}$ & $\begin{array}{l}\text { Combination of Anti-PD-L1 + another therapy used } \\
\text { to treat lung cancer }\end{array}$ & $\begin{array}{l}\text { Bristol-Myers } \\
\text { Squibb }\end{array}$ \\
\hline 0.9230 & $\begin{array}{l}\text { WO2016081384A1 } \\
(2014)\end{array}$ & Combination of Anti-PD-1 + Agonist of OX40 & Roche | Genentech \\
\hline
\end{tabular}

According to the overall patent score and the group of patents analyzed, there is not a perfect patent - the highest score found was 0.9436 out of 1 . The patent with the highest score is a cooperation among Pfizer and Merck who deals with a combination therapy among the Pfizer's 4-1BB agonist (PF-05082566) with the Merck's PD-1 mAb named Keytruda (pembrolizumab) approved by FDA in 2014. In general, the majority of the patents included in the group of the top 10 highest scored deal with combination therapy using immune checkpoint inhibitors (PD-1, PD-L1, CTLA4...). The successful application of the immune checkpoint blockers to treat cancer has recently triggered the development of a new generation of immune modulators which can be more effective if employed in combination (Topalian et al., 2015). Our results are supported by many studies published recently confirming this trend, reinforcing the strength of the model. Zarrabi and $\mathrm{Wu}$ (2018) reported that combination immunotherapies and combination immunotherapy with targeted therapy is shown as the most promising technologies and will have a profound effect at diminishing tumor resistance to therapy, median progression-free survival and overall survival in coming years. Massari et al., (2018) also mentioned that combination between immune-checkpoint inhibitors and other drugs such as target agents, chemotherapy, radiotherapy, other immune agents, and other immunecheckpoint inhibitors could be a key strategy able to overcome the tumor immune escape.

We found a very similar research which associates AHP to rank patents based on multiple experts evaluation for patent portfolio selection (Collan et al., 2013). The authors were the first to include both financial and non-financial metrics in ranking patents according to the moments, using probabilistic moments in characterizing fuzzy financial information. Although our study had similar aims, Collan and co-authors used six "strategic" criteria regarding the aspects of patents to build the decision model, while in our research the patent criteria were 
based on quantitative and qualitative indicators of patents. The use of indicators have also been explored before in association with AHP for patent valuation (Chiu and Chen, 2007). In this study, the authors developed a patent scoring system from the licensor side which included dimensions both from patents and the market indicators. The patents indicators are very similar to the ones we selected for analysis, the difference consists in broader factors of the specific sector analyzed by our research, such as company's attributes and intrinsic attributes of the technologies to be scored.

\section{CONCLUSIONS}

In the present research, we develop a model to predict the emergence of a therapeutic $\mathrm{mAb}$ based on several attributes relative to three main success factors: patent status, the company's profile, and the medical relevance of the mAbs. The attributes quantification results along with its desirability levels provide enough information to rank any patent related to the field through the ES defined by the attributes importance. The most promising mAb deals with the combination therapies using immune checkpoint inhibitors associated with chemotherapy or immunotherapies. The model discussed hereby allows the forecasting of therapeutic mAbs on a patent-level with the highest probability of being emergent in the future according to the criteria analyzed.

Our research has several managerial implications. Companies, research institutions and academia can take advantage of our model to manage their own portfolio as well as to study the portfolio from the competitors. The use of patent ranks can stimulate the decision-making to achieve the highest desirability levels described by our results to reinforce a technology to gain an emerging status in the near future. Our research is also useful to assess the value of patents for a near intention of licensing or technology transfer. Another implication is related to technology assessment as a way to improve business performance in order to choose and control technologies (Azzone and Manzini, 2008), bringing benefits towards their businesses (Ahmad and Christakis, 1979). The method applied in this study can be useful to measure the quality of a company's whole patent portfolio as an increment in a decision to establish a strategic alliance such as mergers and acquisitions, a very frequent strategy in biotech. The present model was carefully distinguished and investigated in this paper. Thus, assured that the findings are not part of an exceptional model but adequate and tested model which stay relevant over the disciplines. Therefore, an emphasis indicates that company can generate value from the interchange and application of the model when examine patents which reflects on its competitive advantage. 
In future studies, we intend to apply the present model to analyze other technological applications, both in the US and in other countries, considering also attributes related to market. A limitation of the study is the field of application, only biotech companies focused in developing monoclonal antibodies for a therapeutic use can take advantage of the model described herein. Another limitation is gathering data to apply the model to other sectors. The proper application of the model must be very consistent with the information management and availability of data from companies, patents and drugs (especially clinical trials). So, the application of the model in other countries will depend on the availability of such information to infer the score of technologies.

\section{REFERENCES}

Ahmad, R.S., Christakis, A.N., 1979. A policy-sensitive model of technology assessment. IEEE Trans. Syst. Man Cybern. SMC-9, 450-8.

Alanazi, H.A., Daim, T.U., Kocaoglu, D.F., 2015. Identify the best alternatives to help the diffusion of teleconsultation by using the Hierarchical Decision Model (HDM), in: Management of Engineering and Technology (PICMET), 2015 Portland International Conference on. IEEE, pp. 422-432.

Ardito, L., Messeni Petruzzelli, A., Albino, V., 2015. From Technological Inventions to New Products: A Systematic Review and Research Agenda of the Main Enabling Factors. Eur. Manag. Rev. 12, 113-147. doi:10.1111/emre.12047

Azzone, G., Manzini, R., 2008. Quick and dirty technology assessment: The case of an Italian Research Centre. Technol. Forecast. Soc. Change 75, 1324-1338. doi:10.1016/j.techfore.2007.10.004

Berg, M., Chen, K., Zissis, G., 1976. A value-oriented policy generation methodology for technology assessment. Technol. Forecast. Soc. Change 8, 401-420. doi:10.1016/00401625(76)90031-7

Callaert, J., Van Looy, B., Verbeek, A., Debackere, K., Thijs, B., 2006. Traces of prior art: An analysis of non-patent references found in patent documents. Scientometrics. doi:10.1007/s11192-006-0135-8

Carlson, R., 2016. Estimating the biotech sector's contribution to the US economy. Nat. Publ. Gr. 34, 247-255. doi:10.1038/nbt.3491

Carpenter, M.P., Narin, F., Woolf, P., 1981. Citation rates to technologically important patents. World Pat. Inf. 3, 160-163. doi:10.1016/0172-2190(81)90098-3

Chadha, A., Oriani, R., 2009. R\&D market value under weak intellectual property rights protection: the case of India. Scientometrics 82, 59-74. doi:10.1007/s11192-009-0042-X

Chan L, Daim T “A Research and Development Decision Model for Pharmaceutical Industry: Case of China" $R \& D$ Management, Vol 48, No 2, 2018, Pages 223 - 242

Chen, S., Wang, Z., 2010. The Evaluation of the Biotechnology Cluster by Fuzzy AHP: Based on the GEM Model, in: Management and Service Science (MASS), 2010 International Conference on. IEEE, pp. 1-4.

Chen, Y.M., Liu, H.H., Liu, Y.S., Huang, H.T., 2016. A preemptive power to offensive patent 
litigation strategy: Value creation, transaction costs and organizational slack. J. Bus. Res. 69, 1634-1638. doi:10.1016/j.jbusres.2015.10.030

Cheung, W.C., Beausoleil, S.A., Zhang, X., Sato, S., Schieferl, S.M., Wieler, J.S., Beaudet, J.G., Ramenani, R.K., Popova, L., Comb, M.J., Rush, J., Polakiewicz, R.D., 2012. A proteomics approach for the identification and cloning of monoclonal antibodies from serum. Nat. Biotechnol. doi:10.1038/nbt.2167

Chiu, Y.J., Chen, Y.W., 2007. Using AHP in patent valuation. Math. Comput. Model. 46, 10541062. doi:10.1016/j.mcm.2007.03.009

Clark, M.R., 1986. Medical applications of monoclonal antibodies. Revis Biol Cel. 9, 1-79.

Collan, M., Fedrizzi, M., Luukka, P., 2013. A multi-expert system for ranking patents: An approach based on fuzzy pay-off distributions and a TOPSIS-AHP framework. Expert Syst. Appl. 40, 4749-4759. doi:10.1016/j.eswa.2013.02.012

Daim, T.U., Yoon, B.-S., Lindenberg, J., Grizzi, R., Estep, J., Oliver, T., 2017. Strategic roadmapping of robotics technologies for the power industry: A multicriteria technology assessment. Technol. Forecast. Soc. Change. doi:10.1016/j.techfore.2017.06.006

Dara, A., Sangamwar, A.T., 2014. Anticancer patent landscape and technology assessment of Indian public-funded research institutes and organizations. Expert Opin. Ther. Pat. 24, 893-912. doi:10.1517/13543776.2014.926329

de Paulo, A.F., Porto, G.S., 2018. Evolution of collaborative networks of solar energy applied technologies. J. Clean. Prod. 204, 310-320. doi:10.1016/j.jclepro.2018.08.344

DiMasi, J.A., Kim, J., Getz, K.A., 2014. The Impact of Collaborative and Risk-Sharing Innovation Approaches on Clinical and Regulatory Cycle Times. Ther. Innov. Regul. Sci. 48, 482-487. doi:10.1177/2168479014521419

Ecker, D.M., Jones, S.D., Levine, H.L., 2015. The therapeutic monoclonal antibody market. MAbs 7, 9-14. doi:10.4161/19420862.2015.989042

Edelman, B., 2004. Explaining the cost of biotech therapies. Biotechnol. Healthc. 1, 37-41.

Elgundi, Z., Reslan, M., Cruz, E., Sifniotis, V., Kayser, V., 2017. The state-of-play and future of antibody therapeutics. Adv. Drug Deliv. Rev. 122, 2-19. doi:10.1016/j.addr.2016.11.004

Ernst \& Young, 2016. Beyond borders: Returning to Earth. Biotechnol. Rep. 2016 Beyond 186.

Estep, J., 2017. Development of a Technology Transfer Score for Evaluating Research Proposals: Case Study of Demand Response Technologies in the Pacific Northwest. Portland State University.

Estep, J., 2015. Development of a technology transfer score to inform the selection of a research proposal. Portl. Int. Conf. Manag. Eng. Technol. 2015-Septe, 1754-1768. doi:10.1109/PICMET.2015.7273115

Eusebi, C.A., Silberglitt, R., 2014. Identification and Analysis of Technology Emergence Using Patent Classification, in: Identification and Analysis of Technology Emergence Using Patent Classification. doi:10.7249/j.ctt14bs2mh.1

Evens, R.P., Kaitin, K.I., 2014. The Biotechnology Innovation Machine: A Source of Intelligent Biopharmaceuticals for the Pharma Industry-Mapping Biotechnology's Success. Clin. Pharmacol. Ther. 95, 528-532. doi:10.1038/clpt.2014.14 
Fernández-Ribas, A., 2010. International patent strategies of small and large firms: An empirical study of nanotechnology. Rev. Policy Res. 27, 457-473. doi:10.1111/j.15411338.2010.00451.x

Gans, J.S., Stern, S., 2003. The product market and the market for "ideas": Commercialization strategies for technology entrepreneurs. Res. Policy 32, 333-350. doi:10.1016/S00487333(02)00103-8

Gebauer, M., Skerra, A., 2009. Engineered protein scaffolds as next-generation antibody therapeutics. Curr. Opin. Chem. Biol. doi:10.1016/j.cbpa.2009.04.627

Geng, X., Kong, X., Hu, H., Chen, J., Yang, F., Liang, H., Chen, X., Hu, Y., 2015. Research and development of therapeutic mAbs: An analysis based on pipeline projects. Hum. Vaccines Immunother. 11, 2769-2776. doi:10.1080/21645515.2015.1074362

Gibson, E.C., 2016. A Measurement System for Science and Engineering Research Center Performance Evaluation.

Grand View Research, 2017. Biotechnology Market Analysis By Application (Health, Food \& Agriculture, Natural Resources \& Environment, Industrial Processing Bioinformatics), By Technology, And Segment Forecasts, 2014 - 2025. San Francisco.

Guellec, D., Van Pottelsberghe De La Potterie, B., 2000. Applications, grants and the value of patent. Econ. Lett. 69, 109-114. doi:10.1016/S0165-1765(00)00265-2

Harlin, M.B., O’Connor, K.A., 2008. Leveraging your biotech intellectual property. Nat. Biotechnol. 26, 607-609. doi:10.1038/bioe.2008.5

Hogaboam, L., Ragel, B., Daim, T., 2014. Development of a Hierarchical Decision Model (HDM) for health technology assessment (HTA) to design and implement a new patient care database for low back pain, in: Proceedings of PICMET '14 Conference: Portland International Center for Management of Engineering and Technology; Infrastructure and Service Integration. Piscataway, NJ, USA, pp. 3511-17.

Jekunen, A., 2014. Decision-making in product portfolios of pharmaceutical research and development - managing streams of innovation in highly regulated markets. Drug Des. Devel. Ther. 8, 2009-2016. doi:10.2147/DDDT.S68579

Jeong, Y., Park, I., Yoon, B., 2016. Forecasting technology substitution based on hazard function. Technol. Forecast. Soc. Change 104, 259-272. doi:10.1016/j.techfore.2016.01.014

Kaplon, H., Reichert, J.M., 2018. Antibodies to watch in 2018. MAbs 10, 183-203. doi:10.1080/19420862.2018.1415671

Kennedy, P.J., Oliveira, C., Granja, P.L., Sarmento, B., 2017. Monoclonal antibodies: technologies for early discovery and engineering. Crit. Rev. Biotechnol. 1-15. doi:10.1080/07388551.2017.1357002

Kim, G., Bae, J., 2017. A novel approach to forecast promising technology through patent analysis. Technol. Forecast. Soc. Change 117, 228-237. doi:10.1016/j.techfore.2016.11.023

Kocaoglu, D.F., 1983. A Participative Approach to Program Evaluation 112-118.

La Merie Publishing, 2017. Blockbuster Biologics 2016: Sales of Recombinant Therapeutic Antibodies \& Proteins. Weikersheim - Germany.

Lanjouw, J.O., Schankerman, M., 2001. Characteristics of Patent Litigation: A Window on 
Competition. RAND J. Econ. 32, 129. doi:10.2307/2696401

Lee, Y.G., Lee, J.D., Song, Y. Il, Lee, S.J., 2007. An in-depth empirical analysis of patent citation counts using zero-inflated count data model: The case of KIST. Scientometrics 70, 27-39. doi:10.1007/s11192-007-0102-z

Li, W., Caberoy, N.B., 2010. New perspective for phage display as an efficient and versatile technology of functional proteomics. Appl. Microbiol. Biotechnol. doi:10.1007/s00253009-2277-0

Liu, C.Y., Wu, H.L., Lee, C.Y., 2018. The relationship between patent attributes and patent litigation: Considering the moderating effects of managerial characteristics. Asia Pacific Manag. Rev. 23, 121-129. doi:10.1016/j.apmrv.2017.05.001

Linstone, H.A., 1999. Decision making for technology executives: using multiple perspectives to improved performance. Artech House Technology Manage.

Ma, Z., Lee, Y., 2008. Patent application and technological collaboration in inventive activities: 1980-2005. Technovation 28, 379-390. doi:10.1016/j.technovation.2007.07.011

Massari, F., Di Nunno, V., Cubelli, M., Santoni, M., Fiorentino, M., Montironi, R., Cheng, L., Lopez-Beltran, A., Battelli, N., Ardizzoni, A., 2018. Immune checkpoint inhibitors for metastatic bladder cancer. Cancer Treat. Rev. 64, 11-20. doi:https://doi.org/10.1016/j.ctrv.2017.12.007

Meyer, M., 2006. Knowledge integrators or weak links? An exploratory comparison of patenting researchers with their non-inventing peers in nano-science and technology, in: Scientometrics. pp. 545-560. doi:10.1007/s11192-006-0129-6

Moorkens, E., Meuwissen, N., Huys, I., Declerck, P., Vulto, A.G., Simoens, S., 2017. The market of biopharmaceutical medicines: A snapshot of a diverse industrial landscape. Front. Pharmacol. 8. doi:10.3389/fphar.2017.00314

Morgan, S., Grootendorst, P., Lexchin, J., Cunningham, C., Greyson, D., 2011. The cost of drug development: A systematic review. Health Policy (New. York). doi:10.1016/j.healthpol.2010.12.002

Moyer, E.D., 2006. Regulatory affairs: Keeping product development on track, in: Alternative Careers in Science. pp. 125-138. doi:10.1016/B978-012589376-3/50040-1

Mudavadi, C., Hogaboam, L., Daim, T.U., 2016. A hierarchical decision model (HDM) for exploring the adoption of electronic health records, in: Management of Engineering and Technology (PICMET), 2016 Portland International Conference on. IEEE, pp. 27702781.

Narin, F., Noma, E., Perry, R., 1987. Patents as indicators of corporate technological strength. Res. Policy 16, 143-155. doi:10.1016/0048-7333(87)90028-X

Nelson, A.L., Dhimolea, E., Reichert, J.M., 2010. Development trends for human monoclonal antibody therapeutics. Nat. Rev. Drug Discov. doi:10.1038/nrd3229

Nie, X., 2013. Green Suppliers Selecting Based on Analytic Hierarchy Process for Biotechnology Industry, in: Proceedings of the International Conference on Information Engineering and Applications (IEA) 2012. Springer, pp. 253-260.

Pereira, C.G., Picanco-Castro, V., Covas, D.T., Porto, G.S., 2018. Patent mining and landscaping of emerging recombinant factor VIII through network analysis. Nat. Biotechnol. 36, 585-590. doi:10.1038/nbt.4178 
Pereira, C.G., Porto, G.S., 2018. Uncovering Innovation Features and Emerging Technologies in Molecular Biology through Patent Analysis, in: Methods in Molecular Biology. pp. 1534. doi:10.1007/978-1-4939-7312-5_2

Phan, K., 2013. Innovation measurement: A decision framework to determine innovativeness of a company. Portland State University.

PhRMA, 2013. Medicines in development: Biologics. Washington, DC.

Pisano, G.P., 2006. Science Business: The Promise, the Reality, and the Future of Biotech. Harvard Bus. Sch. Press 13, 81-82. doi:10.1057/palgrave.jcb.3050059

Porter, A.L., Detampel, M.J., 1995. Technology opportunities analysis. Technol. Forecast. Soc. Change 49, 237-255. doi:10.1016/0040-1625(95)00022-3

Quintella, C.M., Hatimondi, S.A., Santana Musse, A.P., Miyazaki, S.F., Cerqueira, G.S., Moreira, A. de A., 2011. CO2 Capture Technologies: an Overview with Technology Assessment Based on Patents and Articles, in: Gale, J., Hendriks, C., Turkenberg, W. (Eds.), 10th International Conference on Greenhouse Gas Control Technologies. Elsevier Science Bv, Amsterdam, pp. 2050-2057.

Rader, R.A., 2008. (Re)defining biopharmaceutical. Nat. Biotechnol. doi:10.1038/nbt0708-743

Razgaitis, R., 1999. Early-stage technologies : valuation and pricing, Intellectual property series.

Reddy, S.T., Ge, X., Miklos, A.E., Hughes, R.A., Kang, S.H., Hoi, K.H., Chrysostomou, C., Hunicke-Smith, S.P., Iverson, B.L., Tucker, P.W., Ellington, A.D., Georgiou, G., 2010. Monoclonal antibodies isolated without screening by analyzing the variable-gene repertoire of plasma cells. Nat. Biotechnol. 28, 965-969. doi:10.1038/nbt.1673

Roessner, J.D., Frey, J., 1974. Methodology for technology assessment. Technol. Forecast. Soc. Change 6, 163-169. doi:10.1016/0040-1625(74)90015-8

Saaty, T.L., 1980. The analytic hierarchy process: planning. Prior. Setting. Resour. Alloc. MacGraw-Hill, New York Int. B. Co. 287.

Saggy, I., Wine, Y., Shefet-Carasso, L., Nahary, L., Georgiou, G., Benhar, I., 2012. Antibody isolation from immunized animals: Comparison of phage display and antibody discovery via $v$ gene repertoire mining. Protein Eng. Des. Sel. 25, 539-549. doi:10.1093/protein/gzs060

Schuhmacher, A., Gassmann, O., Hinder, M., 2016. Changing R\&D models in research-based pharmaceutical companies. J. Transl. Med. doi:10.1186/s12967-016-0838-4

Serrano, C.J., 2010. The dynamics of the transfer and renewal of patents. RAND J. Econ. 41, 686-708. doi:10.1111/j.1756-2171.2010.00117.x

Sharma, P., Allison, J.P., 2015. Immune checkpoint targeting in cancer therapy: Toward combination strategies with curative potential. Cell 161, 205-214. doi:10.1016/j.cell.2015.03.030

Shaygan, A., Testik, Ö.M., 2017. A fuzzy AHP-based methodology for project prioritization and selection. Soft Comput. 1-11.

Sheikh, N., Daim, T., Kocaoglu, D.F., 2011. Use of multiple perspectives and decision modeling for PV technology assessment, in: 2011 Portland International Conference on Management of Engineering \&amp; Technology (PICMET 2011). Piscataway, NJ, USA, p. 21 pp.-pp. 
Sloane, E.B., Liberatore, M.J., Nydick, R.L., Luo, W., Chung, Q.B., 2003. Using the analytic hierarchy process as a clinical engineering tool to facilitate an iterative, multidisciplinary, microeconomic health technology assessment. Comput. \&amp; Oper. Res. 30, 1447-65.

Storz, U., 2011. Intellectual property protection: Strategies for future antibody inventions. MAbs 3, 310-317. doi:10.4161/mabs.3.3.15530

Storz, U., Flasche, W., Driehaus, J., 2012. IP Issues of Therapeutic Antibodies. pp. 1-16. doi:10.1007/978-3-642-29526-3_1

Testik, Ö.M., Shaygan, A., Dasdemir, E., Soydan, G., 2017. Selecting Health Care Improvement Projects: A Methodology Integrating Cause-and-Effect Diagram and Analytical Hierarchy Process. Qual. Manag. Healthc. 26, 40-48.

The Antibody Society, 2017. Approved Antibodies [WWW Document]. Antib. Soc. URL http://www.antibodysociety.org/news/approved-antibodies/ (accessed 10.12.17)

Topalian, S.L., Drake, C.G., Pardoll, D.M., 2015. Immune checkpoint blockade: A common denominator approach to cancer therapy. Cancer Cell. doi:10.1016/j.ccell.2015.03.001

Trappey, A.J.C., Trappey, C. V., Wu, C.-Y., Lin, C.-W., 2012. A patent quality analysis for innovative technology and product development. Adv. Eng. Informatics 26, 26-34. doi:10.1016/j.aei.2011.06.005

Trappey, C.V., Trappey, A.J.C., Peng, H.-Y., Lin, L.-D., Wang, T.-M., 2014. A knowledge centric methodology for dental implant technology assessment using ontology based patent analysis and clinical meta-analysis. Adv. Eng. Informatics 28, 153-65.

Tsai, W., Erickson, S., 2006. Early-stage biotech companies: strategies for survival and growth. Biotechnol. Healthc. 3, 49-53.

Vallas, S., Kleinman, D., Biscotti, D., 2011. Political structures and the making of US biotechnology. State Innov. US Gov. role Technol. Dev. 57-76.

Van Den Ende, J., Mulder, K., Knot, M., Moors, E., Vergragt, P., 1998. Traditional and Modern Technology Assessment: Toward a Toolkit. Technol. Forecast. Soc. Change 58, 5-21. doi:10.1016/S0040-1625(97)00052-8

Walsh, G., 2014. Biopharmaceutical benchmarks 2014. Nat. Biotechnol. 32, 992-1000. doi:10.1038/nbt.3040

Wang, M.-L., Lin, H.F., Wang, K.W., 2013. The Application of AHP in Biotechnology Industry with ERP KSF Implementation, in: The 19th International Conference on Industrial Engineering and Engineering Management. Springer, pp. 565-574.

Watson, R.H., 1978. Interpretive Structural Modeling-a useful tool for technology assessment? Technol. Forecast. Soc. Change 11, 165-85.

Wynne, B., 1975. The rhetoric of consensus politics: a critical review of technology assessment. Res. Policy 4, 108-158. doi:10.1016/0048-7333(75)90028-1

Zahir, S., 2002. Using the Analytic Hierarchy Process for Quantifying and Classifying Objects with Multiple Attributes. INFOR 40, 149-172.

Zarrabi, K., Wu, S., 2018. Current and Emerging Therapeutic Targets for Metastatic Renal Cell Carcinoma. Curr. Oncol. Rep. 20, 41. doi:10.1007/s11912-018-0684-Z

Zhang, P., Zhang, Y., 2014. AHP based Technology Selection for Emerging Industry, in: Du, W.J., Ma, M. (Eds.), Green Power, Materials and Manufacturing Technology and Applications Iii, Pts 1 and 2. Trans Tech Publications Ltd, Durnten-Zurich, p. 438-+. 